\title{
Dynamically Forced Increase of Tropical Upwelling in the Lower Stratosphere
}

\author{
HELla GARNY AND MARTIN DAMERIS \\ Deutsches Zentrum für Luft- und Raumfahrt, Institut für Physik der Atmosphäre, Oberpfaffenhofen, Germany \\ WILLIAM RANDEL \\ National Center for Atmospheric Research, Boulder, Colorado
}

GREG E. BODEKER

Bodeker Scientific, Alexandra, New Zealand

RUDOLF DECKERT

Deutsches Zentrum für Luft- und Raumfahrt, Institut für Physik der Atmosphäre, Oberpfaffenhofen, Germany

(Manuscript received 12 October 2010, in final form 21 January 2011)

\begin{abstract}
Drivers of upwelling in the tropical lower stratosphere are investigated using the E39C-A chemistryclimate model. The climatological annual cycle in upwelling and its wave forcing are compared to the interim ECMWF Re-Analysis (ERA-Interim). The strength in tropical upwelling and its annual cycle can be largely explained by local resolved wave forcing. The climatological mean forcing is due to both stationary planetaryscale waves that originate in the tropics and extratropical transient synoptic-scale waves that are refracted equatorward.

Increases in atmospheric greenhouse gas (GHG) concentrations to 2050 force a year-round positive trend in tropical upwelling, which maximizes in the lowermost stratosphere. Tropical ascent is balanced by downwelling between $20^{\circ}$ and $40^{\circ}$. Strengthening of tropical upwelling can be explained by stronger local forcing by resolved wave flux convergence, which is driven in turn by processes initiated by increases in tropical sea surface temperatures (SSTs). Higher tropical SSTs cause a strengthening of the subtropical jets and modification of deep convection affecting latent heat release. While the former can modify wave propagation and dissipation, the latter affects tropical wave generation. The dominant mechanism leading to enhanced vertical wave propagation into the lower stratosphere is an upward shift of the easterly shear zone due to the strengthening and upward shift of the subtropical jets.
\end{abstract}

\section{Introduction}

Many model studies have projected a strengthening of the Brewer-Dobson circulation (BDC), and in particular of tropical upwelling in the lower stratosphere, under increased atmospheric greenhouse gas (GHG) loading (Butchart et al. 2006; Garcia and Randel 2008; Deckert and Dameris 2008; McLandress and Shepherd 2009). Upwelling across the tropical tropopause is the main pathway for tropospheric air masses entering

Corresponding author address: Hella Garny, DLR Oberpfaffenhofen, Münchner Str. 20, 82234 Wessling, Germany.

E-mail: hella.garny@dlr.de the stratosphere. Stratospheric concentrations of many trace gases with tropospheric sources therefore depend on the strength of the upwelling (Holton et al. 1995). Because changes in tropical upwelling can induce trends in stratospheric composition, it is important to understand how tropical upwelling might be influenced by changes in climate.

Upwelling in the tropics, forced by extratropical waves, constitutes the equatorial branch of the BDC (Holton et al. 1995; Haynes et al. 1991). However, extratropical wave forcing alone cannot account for the strength and geographical extent of tropical upwelling in the lower stratosphere (Plumb and Eluszkiewicz 1999). Evidence for contributions from tropical wave forcing is growing 
(Boehm and Lee 2003; Kerr-Munslow and Norton 2006; Randel et al. 2008). Randel et al. (2008) suggested that this wave forcing is due to both extratropical waves propagating equatorward and tropical planetary waves generated by latent heat release in deep convection (Gill 1980). Tropical quasi-stationary waves, which dominate the wave spectra in the upper troposphere and lower stratosphere (e.g., Calvo and Garcia 2009), dissipate in the lower stratosphere because of critical level absorption and thermal damping. Specifically, thermal wave damping is determined by the wave frequency divided by the time scale for thermal relaxation (Garcia and Salby 1987) such that wave damping is stronger for waves with low intrinsic frequencies. The background zonal mean wind Doppler shifts the frequency of the waves, so that easterly winds act to reduce the frequency of westward-propagating waves and therefore enhance wave damping. Where wind speeds decrease with height (easterly shear), the frequency of westward-propagating waves decreases with height; thus, damping increases with height, inhibiting vertical wave propagation. Critical layer absorption of waves is also dependent on the background wind, and quasi-stationary waves dissipate in the vicinity of the zero wind line. However, since the zonal wind in the deep tropics is the product of the balance of momentum fluxes by eddies and momentum transport by the mean meridional circulation (Lee 1999), the dissipation of waves also feeds back onto the zonal wind. Therefore, cause and effect relationships in zonal wind and wave dissipation changes are difficult to disentangle and complicate the identification of the underlying mechanisms.

To date, increases in tropical upwelling have not been verified unambiguously in observations. The small vertical velocities in the tropical upper troposphere and lower stratosphere (on the order of millimeters per second) preclude a precise measurement of the magnitude of tropical upwelling. Thompson and Solomon (2005) and Fu et al. (2010) found pronounced decreasing temperatures in the tropical lower stratosphere while Lin et al. (2009) found increasing temperatures in the extratropics, both indicative of a strengthening BDC. Other studies using derived quantities (Engel et al. 2009) found no indication of an increasing meridional circulation. However, given the paucity of measurements in the tropics, relatively short measurement periods, and small trends compared to interannual variability, it is not surprising that the observational evidence is weak. This absence of evidence therefore does not necessarily contradict model simulations.

Many recent studies have sought to understand the causes of increases in the strength of the BDC simulated by chemistry-climate models. While most models show similar increases in tropical upwelling in the lower stratosphere, there is a wider spread in the magnitude of the associated downwelling poleward of the tropics (McLandress and Shepherd 2009; Garcia and Randel 2008; Deckert and Dameris 2008; Sigmond et al. 2004; Fomichev et al. 2007; Oman et al. 2009). Previous studies have shown that the causal chain of increased GHG concentrations leading to increased radiative forcing and thereby elevated SSTs is primarily what drives increases in the BDC (Fomichev et al. 2007; Sigmond et al. 2004; Oman et al. 2009). Specifically, changes in the circulation are driven by the combined effects of changes in resolved wave activity and orographic gravity wave drag (OGWD). Both McLandress and Shepherd (2009) and Garcia and Randel (2008) conclude that OGWD effects are important for explaining changes in upwelling between 20 and $25 \mathrm{~km}$ and in the extratropics. In contrast, in the lower stratosphere effects of changes in resolved waves, and in particular planetary waves, prevail.

Increased forcing of tropical upwelling by resolved waves in the tropical lower stratosphere might result either from changes in wave propagation or from changes in the generation of extratropical or tropical waves. Deckert and Dameris (2008) suggested that the enhanced wave forcing is a consequence of increased tropical wave generation. They argue that a warmer tropical ocean surface enhances deep convection, which in turn excites more large-scale tropical waves. Calvo and Garcia (2009) showed that increased latent heat release in deep convection could be important for the increase in wave forcing. However, they also found that changes in the refractive index led to enhanced propagation of waves into the lower stratosphere. As yet, there is no consistent picture of the processes that lead to enhanced wave forcing and thereby tropical upwelling.

This study analyses the climatology and trends in tropical upwelling in the lower stratosphere simulated with the E39C-A chemistry-climate model (see section 2 for details). The aim is to quantify changes in tropical upwelling and examine potential contributing mechanisms. To identify the drivers of upwelling changes, results from a transient simulation are compared to results from sensitivity simulations designed to investigate individually the atmospheric response to changes in the prescribed boundary conditions. The role of resolved wave forcing in driving tropical upwelling is examined by doing downward control (DC) calculations for different wave components. The origin of large-scale waves, important in the forcing of upwelling, is investigated using Eliassen-Palm (EP) flux diagrams. The calculation of EP fluxes, downward control, and tropical upwelling is performed as in Garny et al. (2009). 


\section{Model description and experimental setup}

The ECHAM4.L39(DLR)/CHEM/ATTILA (E39C-A) is an updated version of ECHAM4.L39-(DLR)/CHEM (E39C) (Hein et al. 2001; Dameris et al. 2005), based on the spectral general circulation model ECHAM4.L39(DLR) (Land et al. 2002) and the chemistry module CHEM (Steil et al. 1998). E39C-A uses the Atmospheric Tracer Transport in a Lagrangian Model (ATTILA) fully Lagrangian advection scheme (Reithmeier and Sausen 2002). The spectral horizontal resolution is T30, and 39 layers extend from the surface to the uppermost layer centered at $10 \mathrm{hPa}$. OGWD is parameterized following Miller et al. (1989). Since nonorographic gravity waves are mainly important for the momentum balance in the upper stratosphere, the 10-hPa upper boundary of the model allows nonorographic gravity wave drag to be neglected. A more complete description of E39C-A is provided in Stenke et al. (2009). The recent extensive intermodel comparison and evaluation project called the second ChemistryClimate Model Validation Activity (CCMVal-2; Eyring et al. 2010) showed that the transition from a semiLagrangian to a fully Lagrangian transport scheme (see also Stenke et al. 2008, 2009) significantly improved the performance of E39C-A compared to its predecessor (E39C). While the model still has some dynamical biases, especially in the middle stratosphere (presumably caused by the 10-hPa upper layer), it generally performs well in the upper troposphere/lower stratosphere and simulates transport in this region well (Eyring et al. 2010; Gettelman et al. 2010; Hegglin et al. 2010) and thus is well suited for studying processes in this region.

The transient simulation used here is the SCN-B2d simulation defined in Eyring et al. (2008). It is designed to simulate the past and future development of the atmosphere, including both anthropogenic and natural variability. Our experiment extends from 1960 to 2049 (following a 10-yr spinup). The 11-yr solar cycle, quasibiennial oscillation (QBO), sulfate aerosol loadings, and radiative effects of major volcanic eruptions are prescribed to 1999 using observations. Thereafter the solar cycle and QBO are repeated periodically and volcanic eruptions are excluded. The prescribed concentrations of $\mathrm{CO}_{2}, \mathrm{CH}_{4}, \mathrm{~N}_{2} \mathrm{O}$, and natural as well as anthropogenic $\mathrm{NO}_{x}$ emissions follow the Special Report on Emissions Scenarios (SRES) A1B scenario (Houghton et al. 2001). Ozone-depleting substance (ODS) concentrations follow the adjusted A1 scenario described in Eyring et al. (2008). SSTs and sea ice cover from the Hadley Centre Global Environmental Model version 1 (HadGEM1) general circulation model (Martin et al. 2006; Johns et al. 2006) constitute the lower boundary conditions. While the use of modeled SSTs rather than observed
TABLE 1 . The sensitivity experiments used in this study with the corresponding year of the GHG concentration and the SSTs used as boundary conditions. All other boundary conditions are as in Ref2000 (see text).

\begin{tabular}{lcl}
\hline \multicolumn{1}{c}{ Run } & GHGs & \multicolumn{1}{c}{ SSTs } \\
\hline Ref2000 & 2000 & Mean 1995-2004 \\
1960GHG & 1960 & Mean 1995-2004 \\
1960SST & 2000 & Mean 1960-69 \\
1960GHG+SST & 1960 & Mean 1960-69 \\
2040GHG & 2040 & Mean 1995-2004 \\
2040SST & 2000 & Mean 2040-49 \\
2040SST+GHG & 2040 & Mean 2040-49 \\
tropSST & 2000 & Mean 1995-2004 + anomaly \\
\hline
\end{tabular}

SSTs significantly affects the climatologies, long-term trends remain unaffected (Garny et al. 2009). The main findings presented here are also valid for a simulation of the past using observed SSTs. A more detailed description of the experimental setup is given in Garny et al. (2009).

To disentangle the effects of changes in the different boundary conditions, multiple sensitivity simulations were performed in addition to the transient simulation. These sensitivity simulations were run in a time-slice mode where the mean climate state over a selected period is simulated using annually repeating boundary conditions. Each time-slice simulation spans 20 years, following a 5-yr spinup. As a reference simulation, the mean state of the atmosphere in 2000 was simulated using boundary conditions fixed at values representative for 2000 (Ref2000); the prescribed SSTs are the HadGEM SSTs averaged from 1995 to 2004. The simulation nudges the QBO to the cycles from 1990 to 2009. A set of sensitivity simulations was performed in which only the SSTs or only the GHG concentrations were changed. All other boundary conditions (e.g., ODS concentrations) remained as in Ref2000. The perturbations in the boundary conditions were chosen to resemble mean conditions for 1960-69 and 2040-49 (i.e., the first and last decade of the transient simulation). Details of the sensitivity simulations are listed in Table 1.

In addition to the above, an idealized sensitivity simulation was performed to quantify the effect of changes in tropical SSTs only (hereafter referred to as tropSST). To incorporate the trends in SSTs likely driving trends in the atmosphere, the mean SST trend from 1970 to 1999 was added to the SSTs used in Ref2000; the 1960s were excluded since SST trends were weaker than during later decades. Between $16.7^{\circ} \mathrm{S}$ and $16.7^{\circ} \mathrm{N}$ the full trend was added to the reference SSTs, with the added trend tapering to linearly zero by $31.5^{\circ} \mathrm{N}$ and $31.5^{\circ} \mathrm{S}$, and a moving average smoother was also applied to the SST anomaly field. The resulting SST anomaly is mostly 

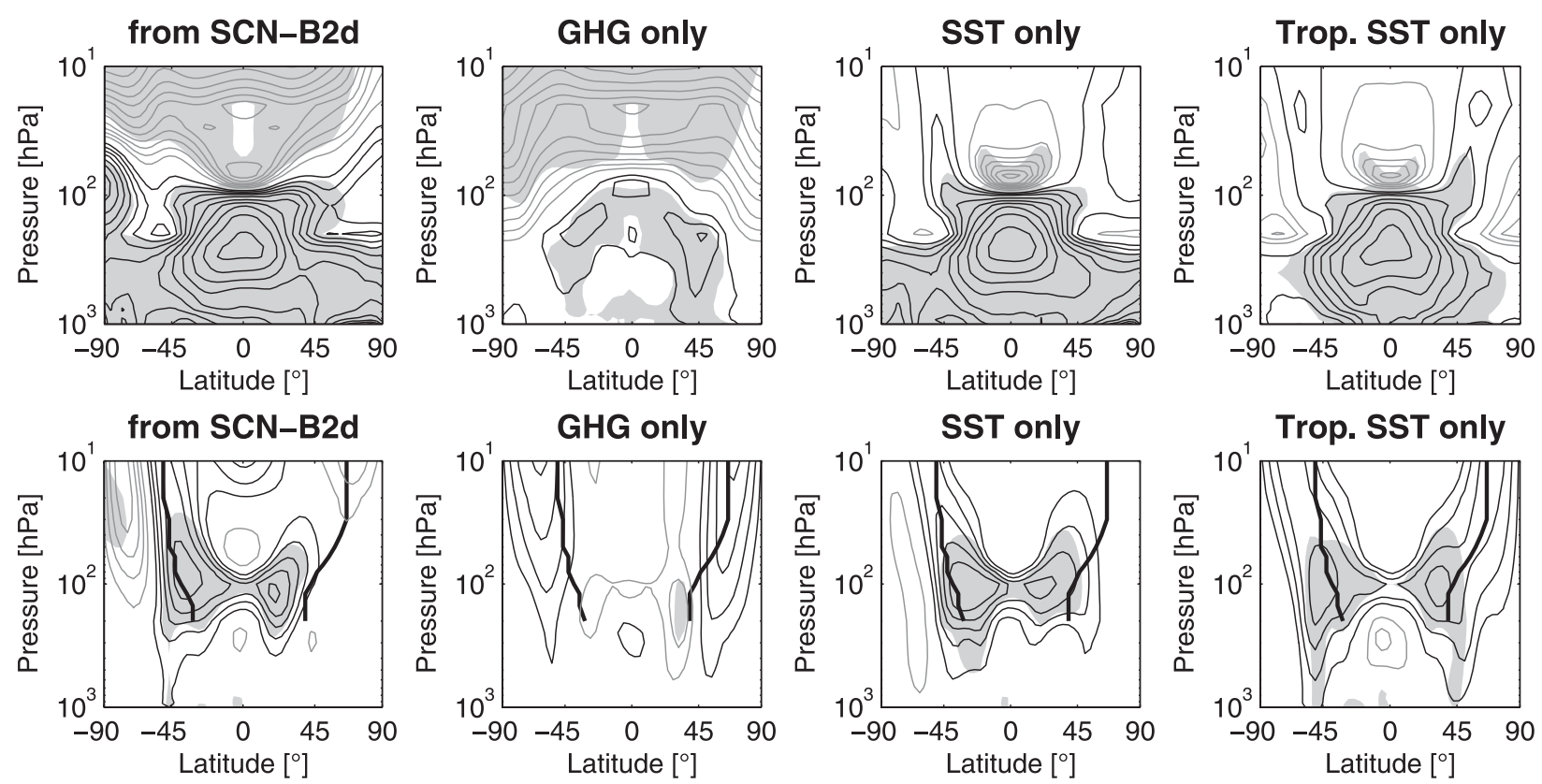

FIG. 1. Response in (top) annual mean temperature and (bottom) zonal wind to changes in GHGs only, SSTs only, and tropical SSTs. (left) The 2040-49 minus 1995-2004 differences from the transient experiment SCN-B2d. The differences between the reference 2000 time slice and (left middle) the 2040GHG, (right middle) 2040SST, and (right) tropSST simulations. Differences are shown as black (positive) and light gray (negative) contours (contour intervals are $0.25 \mathrm{~K}$ and $0.5 \mathrm{~m} \mathrm{~s}^{-1}$, respectively). The location of the jets (i.e., maximum wind speeds) are indicated in the bottom panels as thick black lines. Regions of significant differences (at the 95\% level) are shaded in gray.

positive except for a small region in the equatorial Atlantic.

Since SSTs are prescribed and not interactively coupled in the model, they can be regarded as a separate forcing. In reality, changes in SSTs are caused by elevated GHG concentrations and the two forcings are not necessarily distinguishable. As ODSs also contribute to radiative forcing, the SSTs used here include these effects. In those simulations where ODS concentrations are fixed at 1960 levels, while their radiative forcing is likewise fixed, their influence is felt indirectly through the prescribed SSTs. The temperature and zonal wind response in the 2040SST, 2040GHG, and tropSST simulations is shown in Fig. 1. The response in the corresponding simulations using fixed 1960 boundary conditions is similar but weaker (due to weaker anomalies of the external forcing). The mean response to GHG and SST forcing over the $2000-45$ period is compared to the response over the same period seen in the transient simulation. In addition to SSTs and GHGs, also ODSs and anthropogenic emissions of other gases such as $\mathrm{NO}_{x}$ vary with time in the transient simulation. The temperature response to SST or GHG changes alone shows that tropospheric warming results mainly from the indirect effect of SST increases, while the stratospheric cooling is a direct radiative response to GHG increases (Fig. 1, top). Excluding the warming in the Antarctic lower stratosphere resulting from ozone increases, the sum of the response to
SST and GHG forcing generally resembles the change pattern in the transient simulation. The response to combined forcing by GHGs and SSTs (in the 2040SST + GHG experiment) shows no significant differences to the sum of the response to individual forcings in the 2040SST and 2040GHG experiments (not shown). The enhanced meridional temperature gradient drives a strengthening and upward shift of the subtropical jets (Fig. 1, bottom). Since tropospheric temperature changes are driven by SSTs, the strengthening and shift of the jets are only apparent in response to SST changes. On the other hand, almost no significant changes in zonal mean winds are found when GHGs alone change (Fig. 1, bottom). The atmospheric response to SST and GHG concentration changes shown here agree well with similar previous studies (Fomichev et al. 2007; Sigmond et al. 2004).

The response in zonal mean temperatures and winds to changes in tropical SSTs is shown in Fig. 1 (rightmost panels). The temperature response in the tropics is similar to that for global changes in SSTs. However, differences occur in the extratropics where the troposphere is warmed by global rather than only tropical SST increases. Cooling in the tropical lower stratosphere, on the other hand, also occurs in response to tropical SST increases only. As the temperature response in the tropics enhances the meridional temperature gradient, the zonal wind response to tropical SSTs is again similar to the 

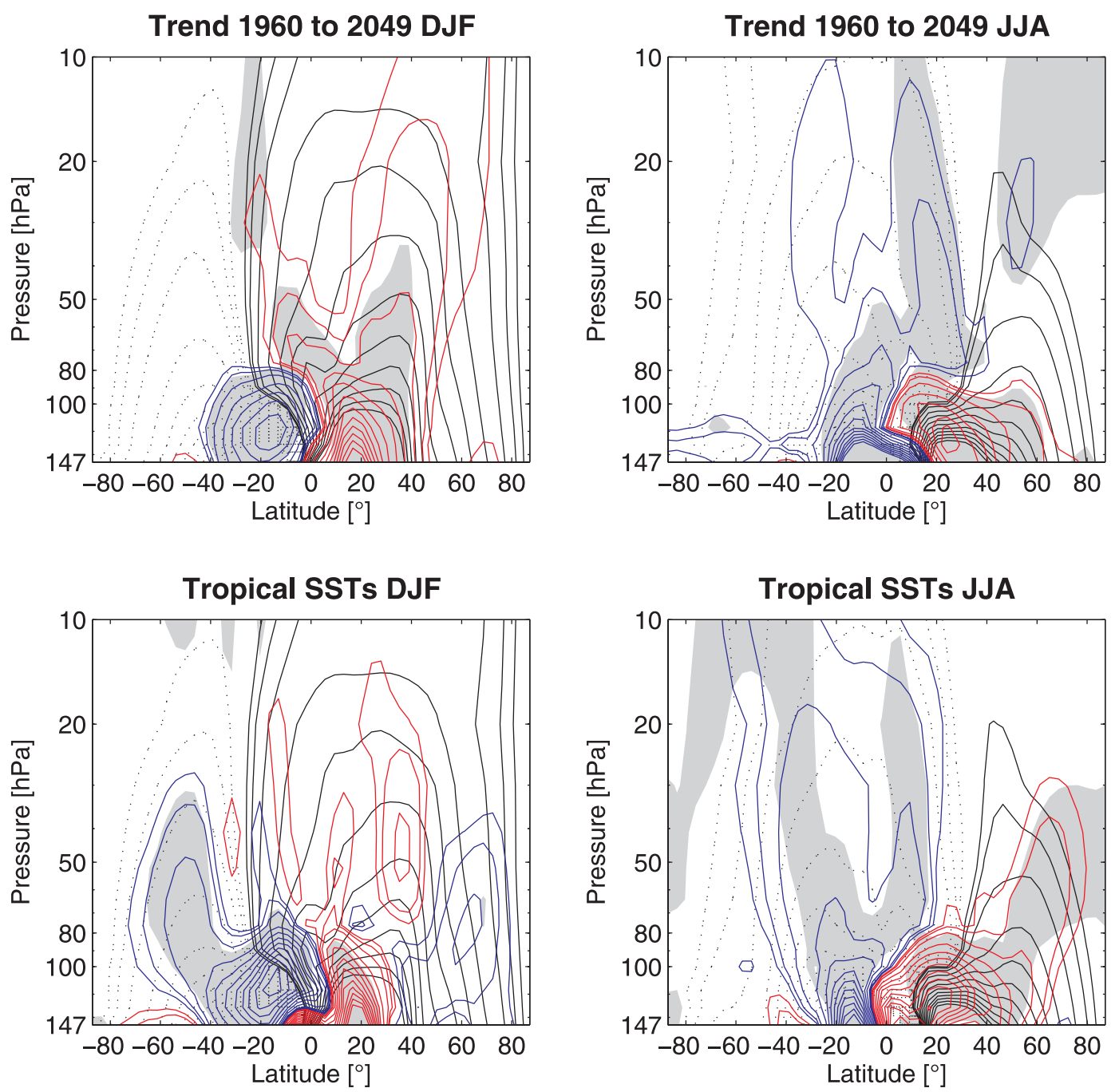

FIG. 2. (top) Climatology of the residual mass-weighted streamfunction (black contours, solid for positive, dashed for negative; contours at $0.25,0.5,1,2,3, \ldots \times 10^{9} \mathrm{~kg} \mathrm{~s}^{-1}$ ) and its trends (red contours for positive, blue for negative; contours at $0.125,0.25,0.5,1,1.5, \ldots \times 10^{8} \mathrm{~kg} \mathrm{~s}^{-1}$ decade $^{-1}$ ) for 1960-2049 in SCN-B2d for (left) DJF and (right) JJA. Gray shading denotes significance at the $95 \%$ level. (bottom) As at top, but showing the difference between the reference (Ref2000) and tropical SST (tropSST) time slices scaled to changes per decade.

response to global SST changes with enhanced subtropical jets. The significant increase in the subtropical jet strength in the tropical SST simulation extends to the surface and is stronger than in response to global SST changes. This is because changing SSTs in the tropics alone artificially enhance the meridional temperature gradient, especially in the extratropical troposphere.

\section{Changes in tropical upwelling}

\section{a. Trends in the transient simulation}

The mean meridional circulation in the stratosphere is quantified using the transformed Eulerian mean residual circulation $\left(\overline{v^{*}}, \overline{w^{*}}\right)$, calculated directly from the wind and heat flux fields. The climatology of the massweighted streamfunction of the residual circulation, together with its long-term linear trend from 1960 to 2049, is shown for the solstice seasons in Fig. 2 (top). Large circulation cells in the winter hemisphere extend across the equator into the summer subtropics. The residual circulation shows a positive trend in the lowermost stratosphere during both seasons. Enhanced upwelling around the equator is balanced by downwelling in the subtropics (around $20^{\circ}-40^{\circ}$ ). Statistically significant trends are mostly confined to altitudes below approximately $50 \mathrm{hPa}$. Significant increases at higher levels are seen only in the summer subtropics in a narrow latitude band, with changes of opposite sign compared to the 

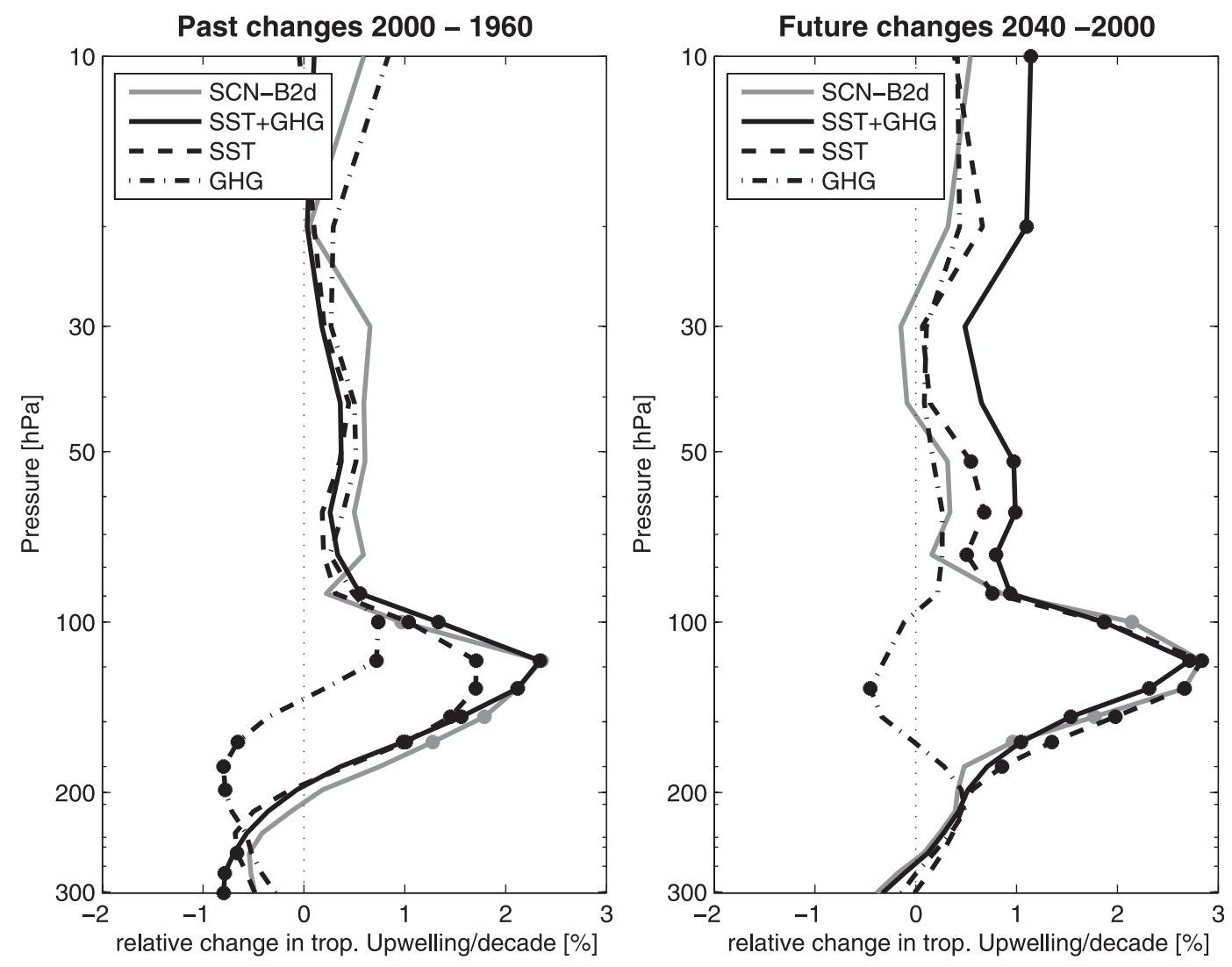

FIG. 3. Annual mean relative changes in tropical upwelling (\% decade ${ }^{-1}$ ) for (left) the past (1995-2004 minus 1960-69) and (right) the future (2040-49 minus 1995-2004). Shown are the differences from SCN-B2d (gray), the response to SST changes only (dashed), the response to GHG changes only (dashed-dotted), and the response to combined GHG and SST changes (solid black); see text for details. Levels at which the differences are significant at the $95 \%$ level are marked with a dot.

lowermost stratosphere. The trends in the residual circulation are similar but mirrored during the solstice seasons. During the equinox seasons [March-May (MAM) and September-November (SON)] the circulation increases in the lower stratosphere in the (sub)tropics with a similar pattern (not shown). In general, it is found that the trend pattern in the residual circulation in the lower stratosphere is insensitive to the choice of period (e.g., only years until 2000 or only after 2000).

Vertically resolved relative changes in tropical upwelling over the past and future are shown in Fig. 3 (gray lines). Significant increases in tropical upwelling are confined to the lowermost stratosphere (below $80 \mathrm{hPa}$ ) and maximize below $100 \mathrm{hPa}$. For individual seasons, significant upwelling changes occur also in the midstratosphere (above $50 \mathrm{hPa}$, not shown), but the strong increase at low levels is consistent throughout the year.

Total tropical upwelling is quantified at each level as the integrated upward mass flux between $60^{\circ} \mathrm{N}$ and $60^{\circ} \mathrm{S}$ where $\overline{w^{*}}$ is positive (i.e., upward). Different methods can be used to calculate upwelling, either integrating over fixed latitudes (e.g., $\pm 20^{\circ}$ ) or varying the boundaries according to the region of upwelling, with substantially different outcomes. The changes shown in Fig. 3 are quantitatively different when integrating over $\pm 20^{\circ}$, but the strongest increase still occurs in the lowermost stratosphere (not shown).

\section{b. Drivers of upwelling changes}

Because deterministic changes in the modeled climate state are known to be forced by the prescribed boundary conditions, simulations can be designed to separate the effects of individual boundary conditions. The sensitivity simulations detailed in section 2 were used to disentangle the effects of SSTs and GHGs in driving changes in tropical upwelling. As shown in section 2, the GHG-only simulations result mainly in stratospheric cooling, while the SST-only simulations result in tropospheric warming and associated strengthening of the subtropical jets. The response of tropical upwelling to SST, GHG, and combined changes in SSTs and GHGs is determined by calculating the relative differences between 

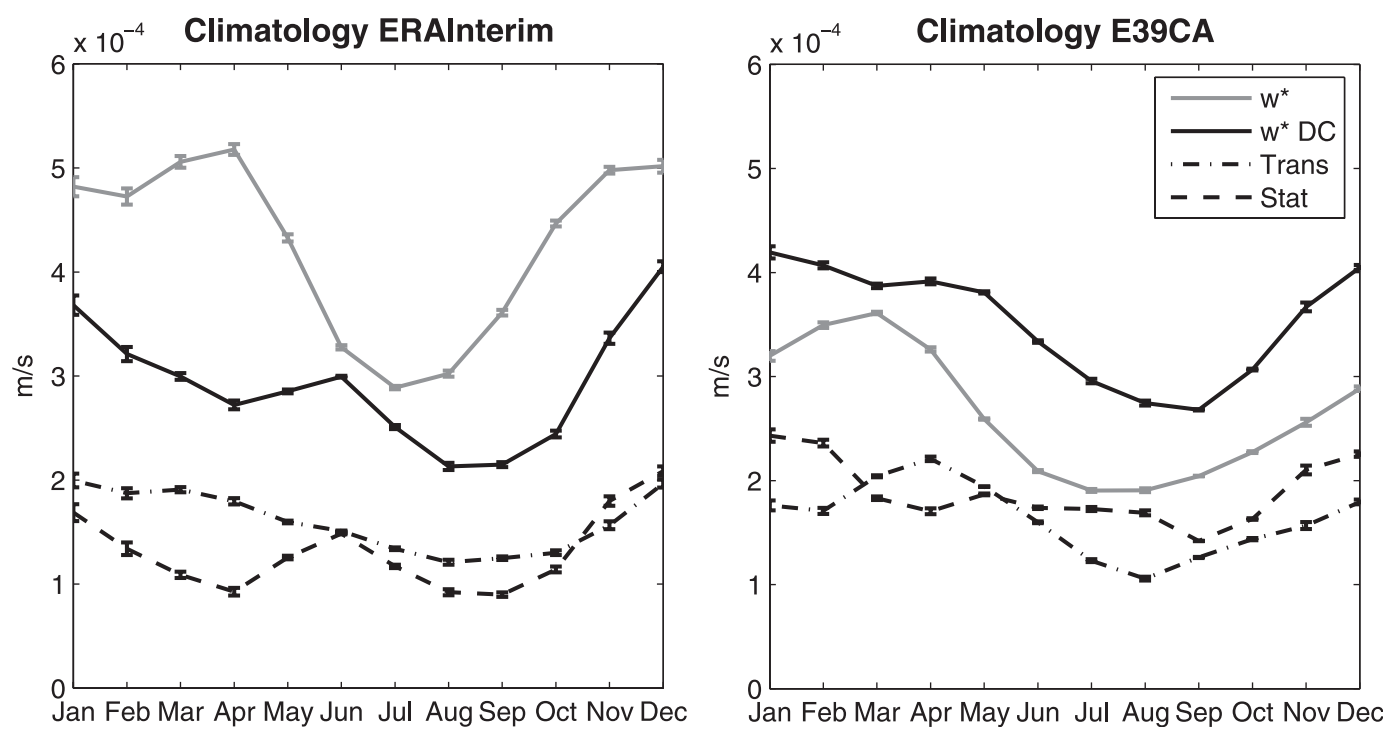

FIG. 4. Annual cycle in mean $\overline{w^{*}}$ between $20^{\circ} \mathrm{N}$ and $20^{\circ} \mathrm{S}$ at $100 \mathrm{hPa}$ (gray), $\overline{w_{\mathrm{DC}}^{*}}$ from downward control using EP fluxes as forcing (solid black), and $\overline{w_{\mathrm{DC}}^{*}}$ from downward control using only stationary (dashed) and only transient (dashed-dotted) wave components, using (left) ERA-Interim climatology from 1989 to 2008 and (right) E39C-A climatology from 1960 to 2049.

Ref2000 and 1960SST, 1960GHG, and 1960GHG +SST, respectively (Fig. 3, left). Figure 3 (right) shows the corresponding relative differences for the " 2040 " timeslice simulations. Changes in tropical upwelling in the transient simulation (gray line in Fig. 3) are largely reproduced when only changes in SSTs are applied. The response in upwelling to GHG concentration changes, on the other hand, is relatively small and differs in sign from past to future. The simulations with combined SST + GHG changes show that the effects of SSTs and GHGs are approximately linearly additive at most levels [in agreement with Sigmond et al. (2004) and Fomichev et al. (2007)]. Furthermore, the pattern of changes in the residual circulation due to SST changes is similar to the pattern derived from the transient simulation (not shown). Changes in SSTs during individual seasons can also be identified as drivers of changes in tropical upwelling.

The response in the residual circulation to tropical SST increases alone (i.e., the difference between tropSST and Ref2000 time-slice simulations) is shown in Fig. 2 (bottom). The meridional circulation is strengthened in the lowermost stratosphere, enhancing upwelling in the deep tropics and inducing anomalous subtropical downwelling. This resembles the trend pattern in the transient experiment over 90 years (Fig. 2, top).

The experiments with global and tropical SST changes both show strong tropospheric warming and associated strengthening of the subtropical jets. The fact that tropical upwelling changes much as in the transient simulation indicates that the processes leading to the increased upwelling are associated with changes in the tropical tropospheric climate.

\section{Wave forcing of tropical upwelling}

\section{a. Downward control}

The residual circulation forced by resolved waves is calculated here using the DC principle (Haynes et al. 1991). In contrast to the total mass flux, which was integrated between the turn-around latitudes (Fig. 3), $w^{*}$ calculated over a fixed latitude band is used to quantify upward motion in the tropics. Fixed latitudes are used because otherwise problems occur in the DC calculation. The latitudinal structure of $\overline{w^{*}}$ is somewhat patchy and as a result the turnaround latitudes are very variable.

The 1960-2049 mean of $\overline{w^{*}}$ averaged between $20^{\circ} \mathrm{S}$ and $20^{\circ} \mathrm{N}$ is shown for E39C-A in Fig. 4 together with the 1989-2008 mean calculated from the interim European Centre for Medium-Range Weather Forecasts (ECMWF) Re-Analysis (ERA-Interim). Because the E39C-A mean calculated from 1989 to 2008 is very similar to that shown in Fig. 4, the results are insensitive to these differences in averaging period. The absolute values of $\overline{w_{\mathrm{DC}}^{*}}$ from E39C-A are within $10 \%-20 \%$ of those from ERA-Interim, and the annual cycle is similar. However, the directly calculated $\overline{w^{*}}$ is lower than $\overline{w_{\mathrm{DC}}^{*}}$ in the model but higher in the reanalysis. The 

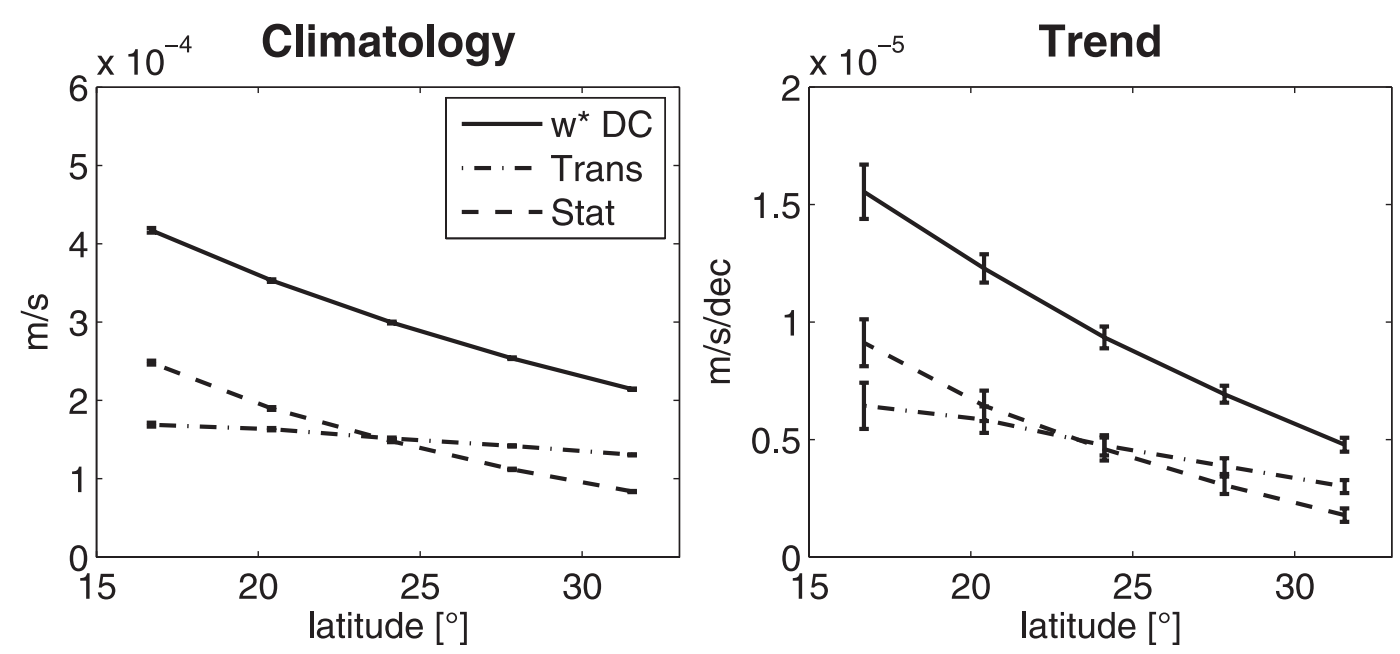

FIG. 5. Annual mean $\overline{w_{\mathrm{DC}}^{*}}$ at $100 \mathrm{hPa}$ calculated using the DC principle, as a function of the averaging latitude bounds; $\overline{w_{\mathrm{DC}}^{*}}$ is shown with stationary waves as forcing only (dashed), with transient waves only (dashed-dotted), and in total (the sum; solid). (left) Climatology over $90 \mathrm{yr}$; (right) trend calculated over these $90 \mathrm{yr}$.

reasons for the overestimation of $\overline{w^{*}}$ by downward control in the model are not known, but it might be caused by the way gravity wave drag is treated or result from the low upper boundary at $10 \mathrm{hPa}$ of E39C-A. The annual cycles of direct $\overline{w^{*}}$ in the model and reanalysis agree well, with minimum values during July and maximum values during northern spring. In both cases the minimum occurs about 1-2 months earlier than in $\overline{w_{\mathrm{DC}}^{*}}$ and the maximum during spring is absent in $\overline{w_{\mathrm{DC}}^{*}}$ Since $\overline{w_{\mathrm{DC}}^{*}}$ includes only resolved waves, the common features in $\overline{w^{*}}$ might result from the additional forcing by orographic gravity waves (which is parameterized in both cases). The discrepancy between the absolute values in $\overline{w^{*}}$ in E39C-A compared to the reanalysis might arise from nonorographic gravity wave forcing, which is neglected in E39C-A, or from orographic gravity wave drag that occurs at different locations due to different background zonal winds. The low upper lid in E39C-A at $10 \mathrm{hPa}$ might also confound the comparison, and so do uncertainties in the reanalysis data, especially in the tropics (Simmons et al. 2006). However, the DC analyses do show that upwelling in the tropics can, in large part, be explained by forcing of resolved waves.

In E39C-A and in ERA-Interim, transient and stationary waves contribute about equally to the wave forcing within $\pm 20^{\circ}$ latitude. Stationary wave forcing is stronger during the solstice seasons than during the equinox seasons, and the forcing is stronger during northern winter than during southern winter. During the equinox seasons, the relative importance of transient waves is enhanced, and transient wave forcing minimizes during August both in the model and the reanalysis.
Only the maximum during northern spring in E39C-A is absent in ERA-Interim. In general the relative contribution of transient waves is slightly higher in ERAInterim than in E39C-A. The relative contributions of stationary and transient waves depend on the choice of the latitude bounds. Figure 5 (left) shows $\overline{w_{\mathrm{DC}}^{*}}$ as a function of the latitude bounds, ranging from $\pm 15^{\circ}$ to $\pm 32^{\circ}$. For latitudes lower than about $15^{\circ}$, DC cannot be applied (as the meridional gradient of angular momentum becomes zero), while for latitudes higher than approximately $35^{\circ}$ the averaging would occur over regions of up- and downwelling and would therefore not be meaningful. As Fig. 5 (left) shows, $\overline{w_{\mathrm{DC}}^{*}}$ forced by stationary waves increases with decreasing latitude bounds, doubling within $\pm 15^{\circ}$ latitude compared to $\pm 30^{\circ}$ latitude. In contrast, the forcing by transient waves increases only slightly with decreasing latitude bounds, so that equatorward of approximately $25^{\circ}$ the stationary wave forcing exceeds the transient wave forcing. The contribution of different wave types to forcing of tropical upwelling is therefore sensitive to the latitudinal averaging region chosen. The annual cycle in upwelling averaged over different latitude bands (not shown) is similar to that shown for $\pm 20^{\circ}$ in Fig. 4.

The contribution to the forcing of upwelling by waves of different horizontal wavenumber (WN) is demonstrated in Fig. 6. Forcing by the sum of planetary (WN 1-3) stationary waves (left) as well as by synoptic-scale transient waves has a quasi-semiannual cycle. The forcing by planetary stationary waves is strongest during the solstice seasons, with both wavenumber 1 and 3 being important during northern winter while during southern winter the forcing is almost entirely due to wavenumber 1 

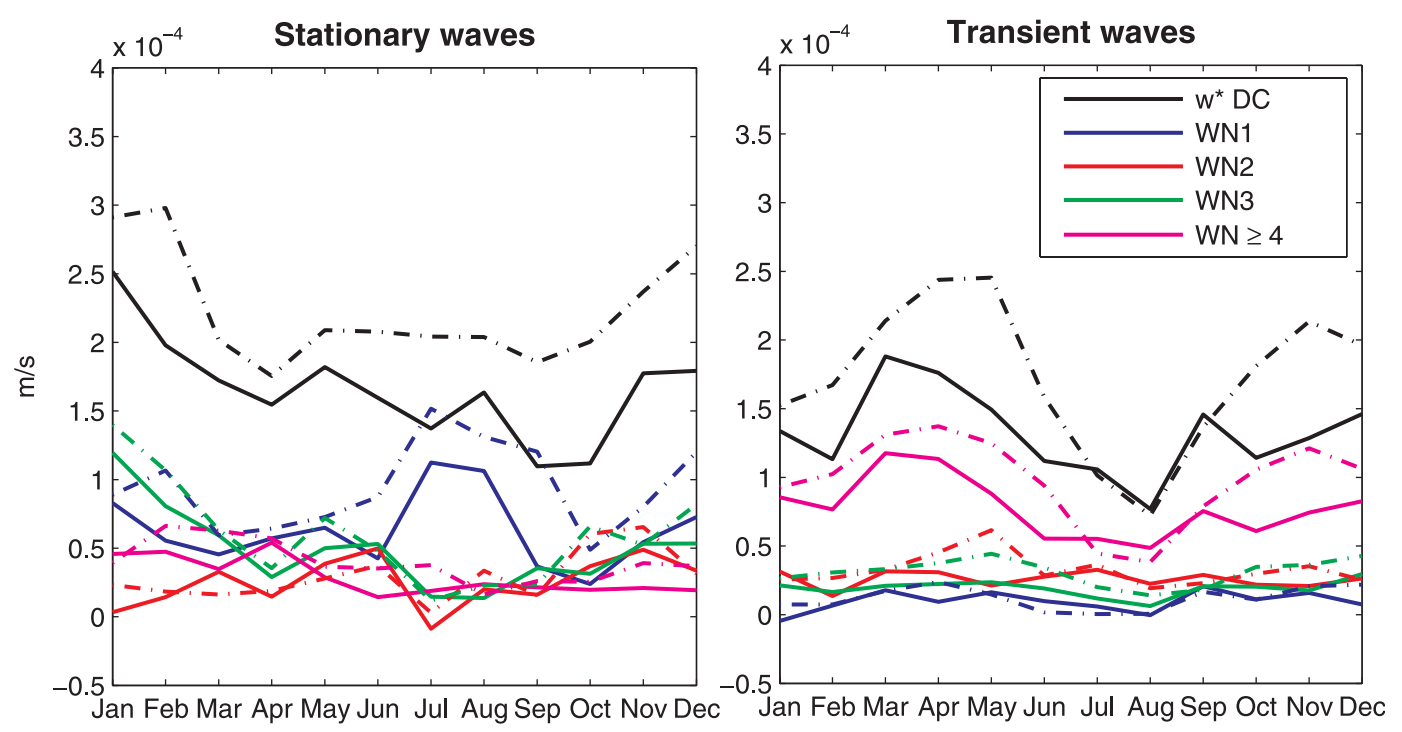

FIG. 6. As in Fig. 4, but for (left) stationary waves only and (right) transient waves only, and for individual wavenumbers 1-3 and wavenumbers $\geq 4$. Solid lines are 1960-69 climatological values; dashed-dotted lines are 2040-49 climatological values.

waves. Forcing of upwelling by transients is dominated by synoptic-scale waves ( $\mathrm{WN} \geq 4$ ), maximizing during the equinox seasons.

The 1960-2049 trend in mean $\overline{w^{*}}$ in E39C-A is positive throughout the year (Fig. 7, left), with largest increases around northern winter and smallest increases during northern summer. The ERA-Interim reanalyses are not available over a sufficiently long period to analyze long-term trends. The relative trend is largest during October $\left(\sim 5 \%\right.$ decade $\left.^{-1}\right)$ and smallest during August $\left(\sim 1.5 \%\right.$ decade $\left.^{-1}\right)$ and lies around $3.5 \%$ decade $^{-1}$ through the rest of the year. The agreement of positive trends in mean $\overline{w_{\mathrm{DC}}^{*}}$ and in the directly calculated $\overline{w^{*}}$ indicates that the changes in upwelling are driven by changes in resolved wave forcing. Both stationary and transient waves contribute to the changes in upwelling, and trends in both are strongly seasonally dependent. In solstice seasons, the relative contribution by stationary waves is largest. The changes in the forcing by transient waves have a quasi-semiannual cycle with strongest increases during the equinox seasons (especially during northern spring, while the second peak is shifted toward late autumn). The dependence of trends in forcing on the latitudinal bounds behaves as in the climatological mean, with the importance of stationary waves increasing with decreasing latitude (see Fig. 5, right). Furthermore, the relative importance of waves of different scale in forcing upwelling also remains similar in the future, with forcing by stationary planetary waves maximizing in the solstice seasons and forcing by transient synoptic-scale waves maximizing during the equinox seasons (Fig. 6).
The similarity of the structure in the trends and in the climatology suggests that the forcing is enhanced equally for all wave classes, with no class being favored in a future climate.

In section $3 b$ it is shown that the response of the residual circulation to changes in tropical SSTs resembles the long-term trends, suggesting that changes in tropical SSTs drive the long-term changes in the transient simulations. Given this, the trends in the dynamical forcing of upwelling are compared to the response of the forcing to tropical SST changes (shown in Fig. 7, right). As in the transient simulation, upwelling increases throughout the year and the increase is forced by resolved waves. Furthermore, the magnitude of the trend is similar. The seasonal dependence of the relative contribution of stationary versus transient waves is not reproduced in the tropical SST simulation. However, the response in tropical upwelling in wave fluxes in the tropical lower stratosphere is robust for the sensitivity simulation and also for subperiods in the transient simulations. This indicates that the relative contributions of transient and stationary waves might not be crucial for determining the response in tropical upwelling.

\section{b. EP fluxes}

In the previous section it is shown that tropical upwelling in the lower stratosphere and changes therein are largely driven by resolved wave forcing. EP fluxes are now analyzed to investigate the origin of the waves causing the forcing in the (sub)tropics. 

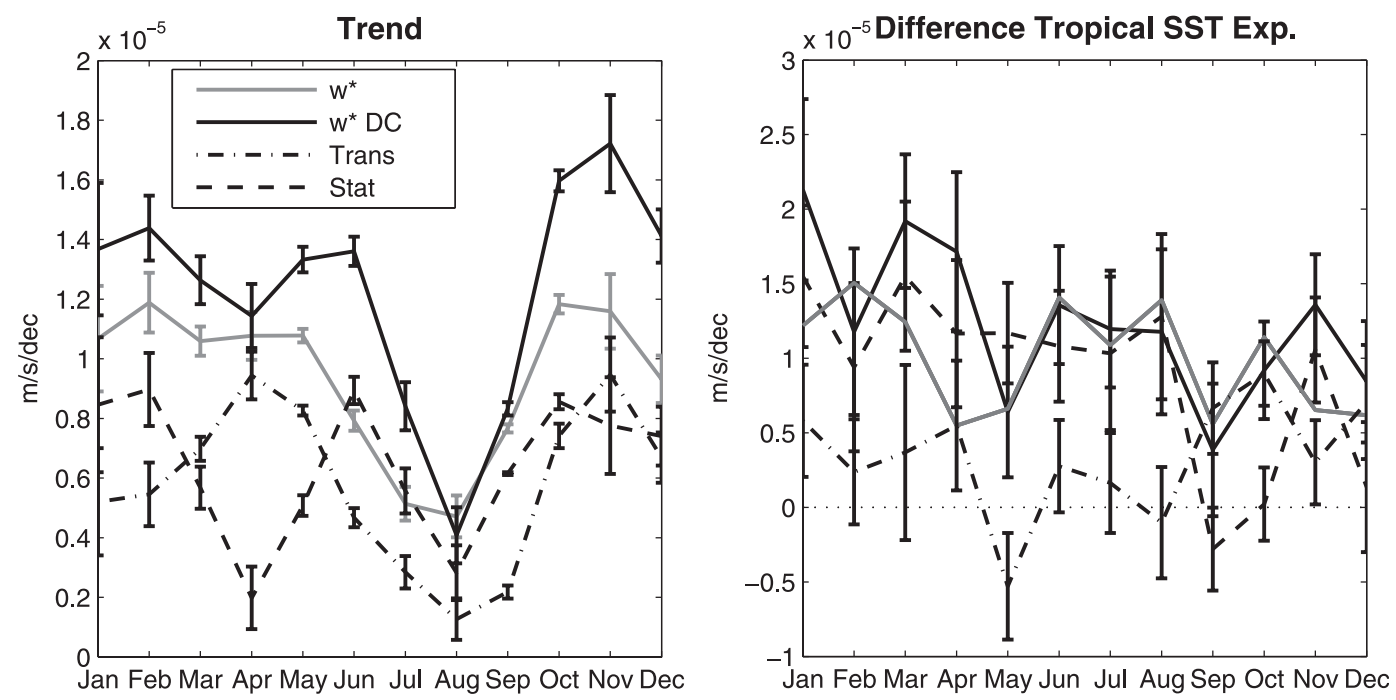

FIG. 7. As in Fig. 4, but for (left) the linear trend from the transient experiment over 1960-2049 and (right) the response to changes in tropical SSTs (the difference tropSST - Ref2000 scaled to change per decade). The error bars denote the 1- $\sigma$ uncertainty in the trends and the differences, respectively.

\section{1) SOlstice SEAsons}

The 1989-2008 climatology in EP fluxes for northern winter [December-February (DJF)] for stationary and transient waves for E39C-A is shown in Fig. 8 (top). This period was selected to match that used for ERA-Interim (see below). The climatology from 1960 to 2049 is qualitatively similar. The pattern in northern summer is similar to DJF but mirrored about the equator (not shown).

In the tropical lower stratosphere, EP fluxes propagate upward from the troposphere, but the waves dissipate strongly at levels below $80 \mathrm{hPa}$. In the mean, zonal winds in the tropical stratosphere are easterly (since easterly phases of the QBO show higher wind speeds than westerly phases); thus, vertical propagation of waves with positive phase speeds is inhibited.

The climatology of EP fluxes shows that waves propagating into the tropical lower stratosphere are of both tropical and extratropical origin. The extratropical contribution consists mostly of transient waves that propagate upward in the midlatitude troposphere and are refracted toward the equator, contributing to EP flux convergence in the subtropics. In the upper troposphere of the summer hemisphere, EP flux divergence occurs south of the equator. This source region is indicative of the generation of tropical waves. On the winter side of the equator, a local maximum of EP flux convergence by stationary waves is found at around $10^{\circ}-20^{\circ}$ latitude and $200 \mathrm{hPa}$. This region of strong EP flux convergence is due to both the dissipation of tropically generated waves and the dissipation of waves generated in midlatitudes and refracted equatorward. However, in the tropical lower stratosphere, stronger EP flux convergence of stationary waves occurs in the summer hemisphere compared to the winter hemisphere [this is also true during June-August (JJA); not shown] and arises from the dissipation of upward-propagating tropical waves.

For comparison, the climatology of EP fluxes from ERA-Interim is shown in Fig. 9. Modeled and observed patterns and magnitudes of EP fluxes and the associated forcing generally agree qualitatively well. The stationary wave generation region in the tropics is apparent in ERA-Interim at a similar location to E39C-A, although the magnitude is smaller. The contribution of transient waves in E39C-A also closely resembles that in ERAInterim, with mainly extratropical wave fluxes and contributions to EP flux convergence in the subtropics.

Figure 10 (top) shows the long-term trend in the stationary component of the EP fluxes for both solstice seasons. The wave forcing during the solstice seasons increases mostly due to stationary waves, and therefore the stationary wave EP fluxes are shown to elucidate the origin of changes in these wave fluxes. Significant increases in EP flux convergence in the lower stratosphere (sub)tropics of the summer hemisphere are found in both seasons. The strong increase in convergence stems from stronger upward EP fluxes in the upper troposphere and lower stratosphere in the summer hemisphere.

During DJF, in the tropical upper troposphere, both regions of increases and decreases in EP flux divergence are apparent. In the wave source region (dashed contour in Fig. 10), decreases in EP flux divergence occur at 
Climatology SCN-B2d 1989-2008 DJF stationary

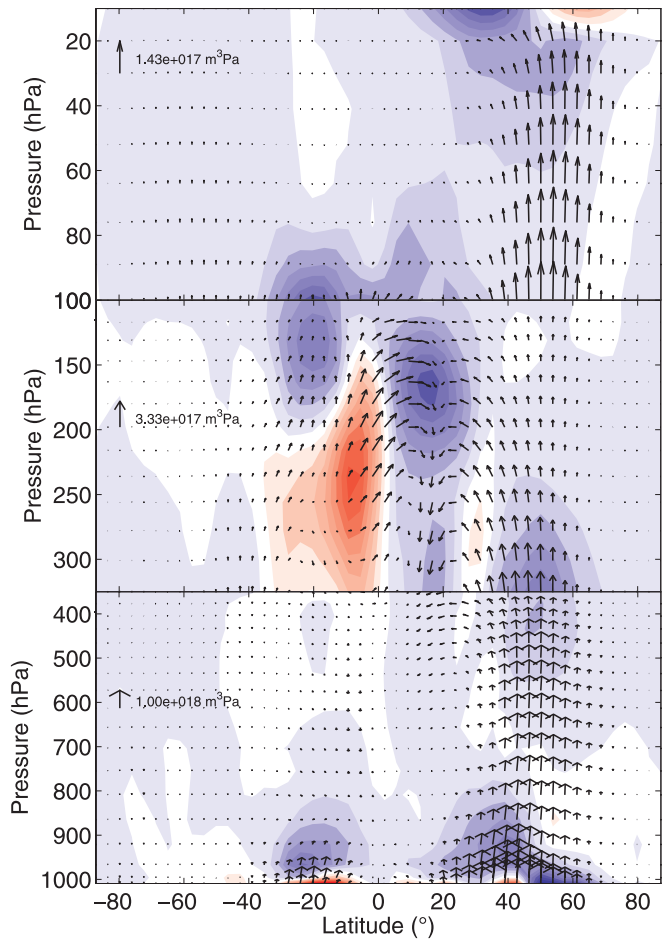

Climatology SCN-B2d 1989-2008 MAM stationary

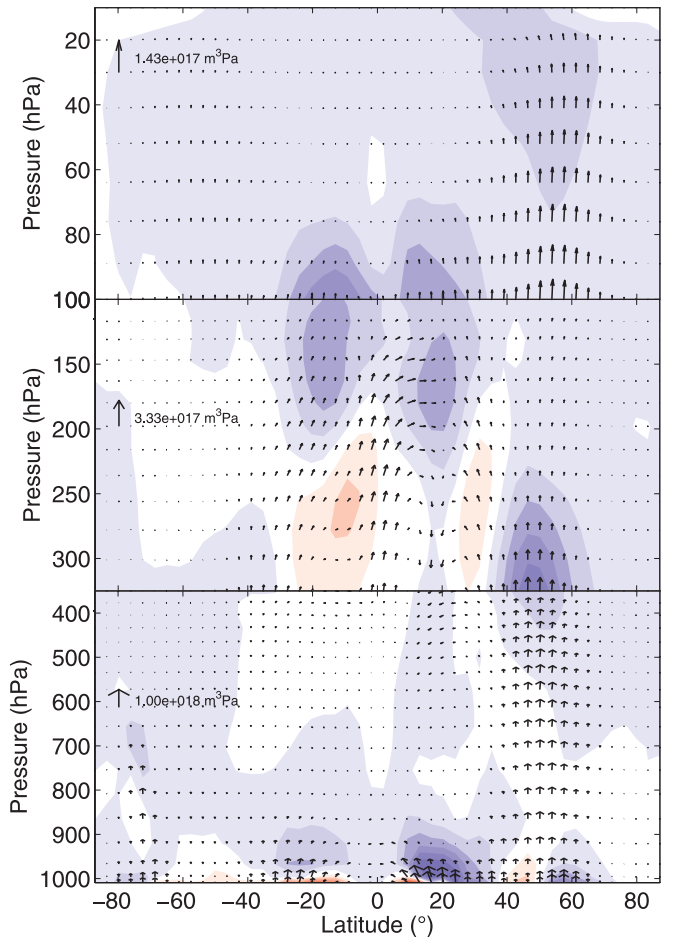

Climatology SCN-B2d 1989-2008 DJF transient
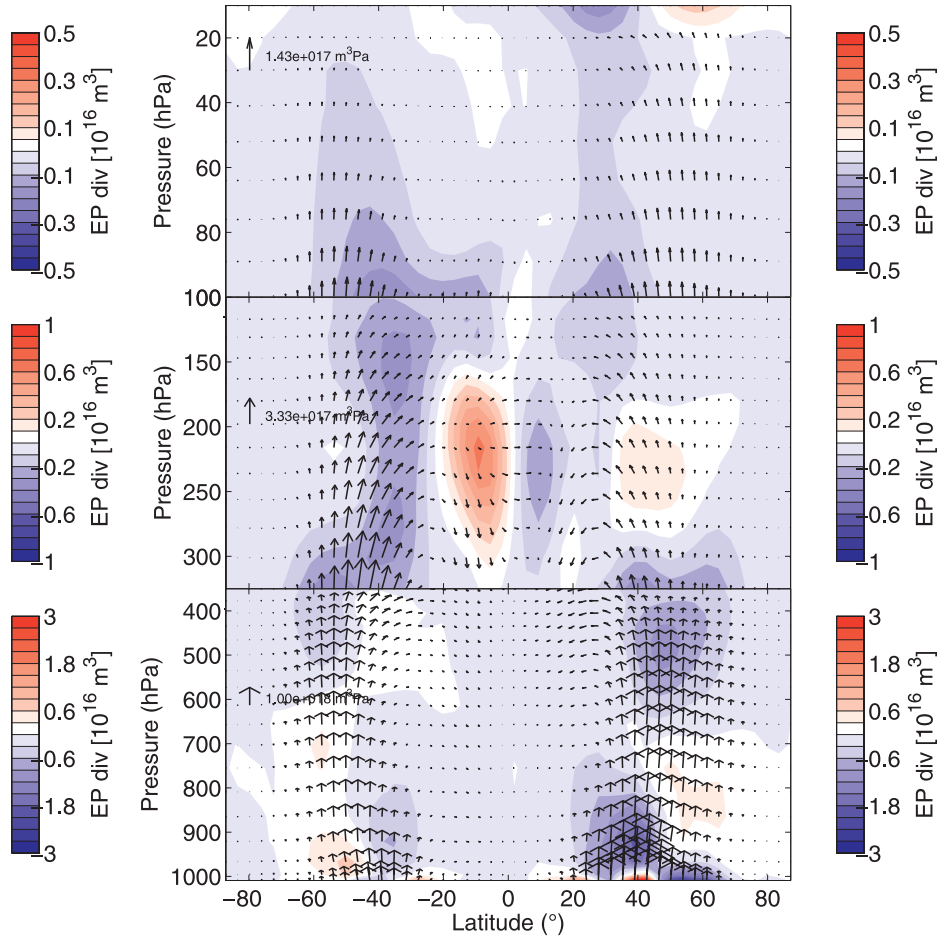

Climatology SCN-B2d 1989-2008 MAM transient
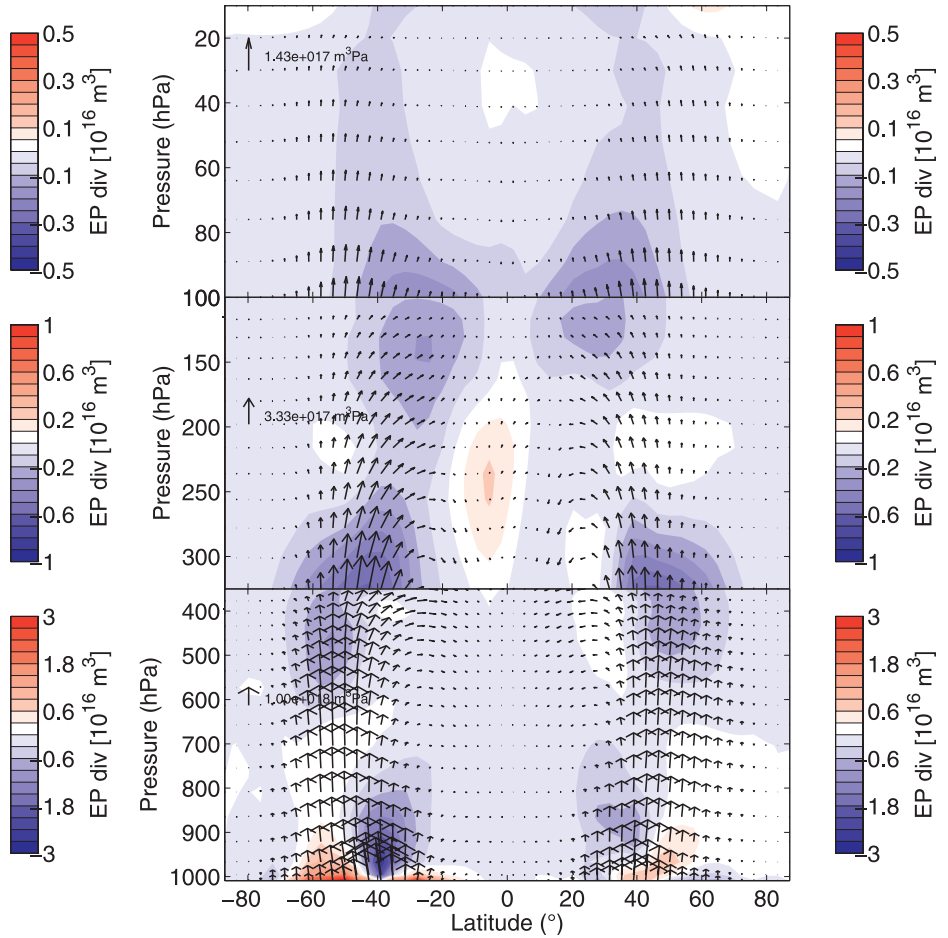

FIG. 8. Climatologies (1989-2008 from SCN-B2d) of EP fluxes (black arrows) and EP divergences (colors) for three different height regions. The scaling of the EP fluxes and divergences is indicated by the scale arrow and the color bar in each panel. EP fluxes of (left) stationary and (right) transient waves in (top) DJF and (bottom) MAM are shown. 

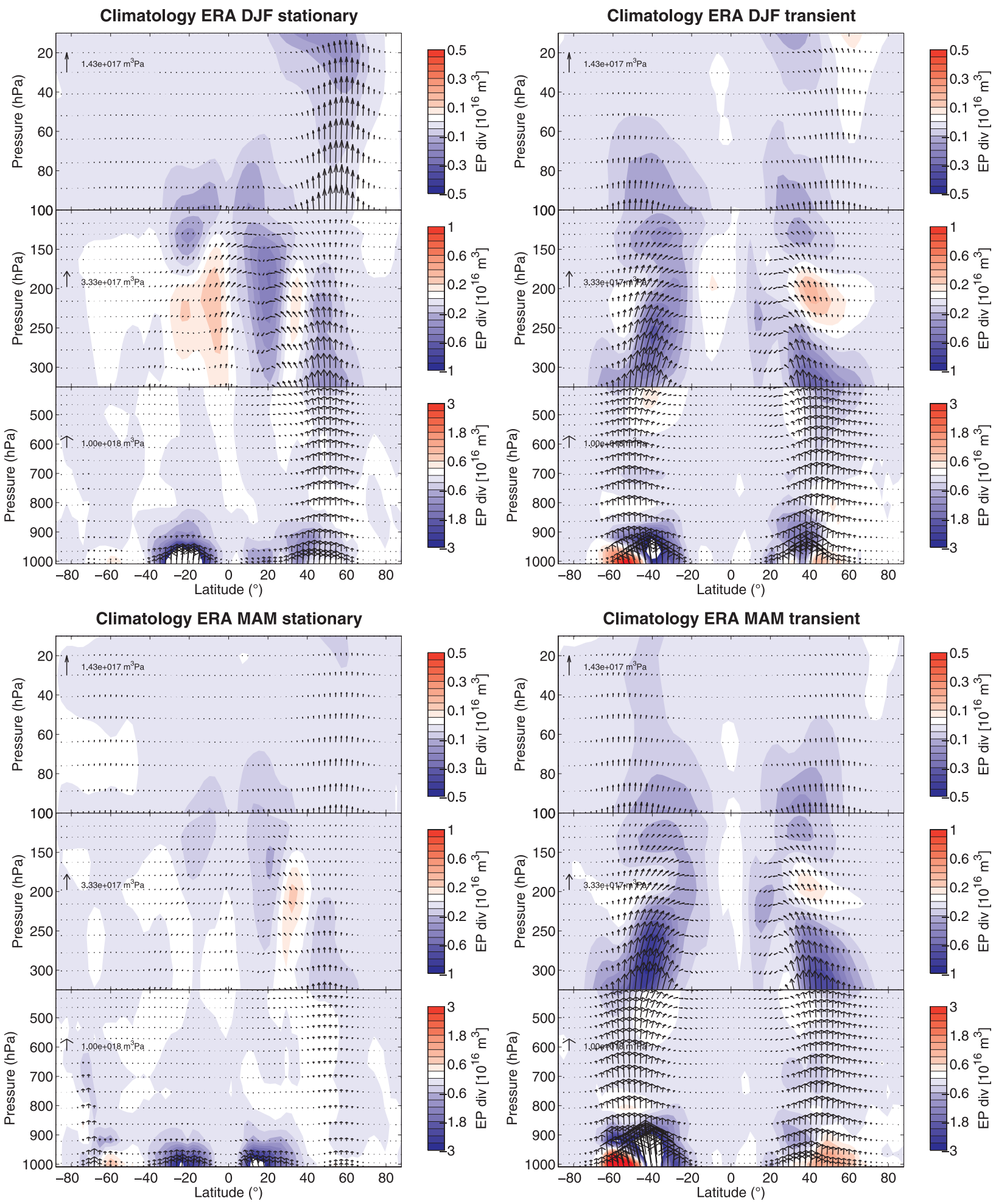

FIG. 9. As in Fig. 8, but for the ERA-Interim climatology over 1989-2008. 

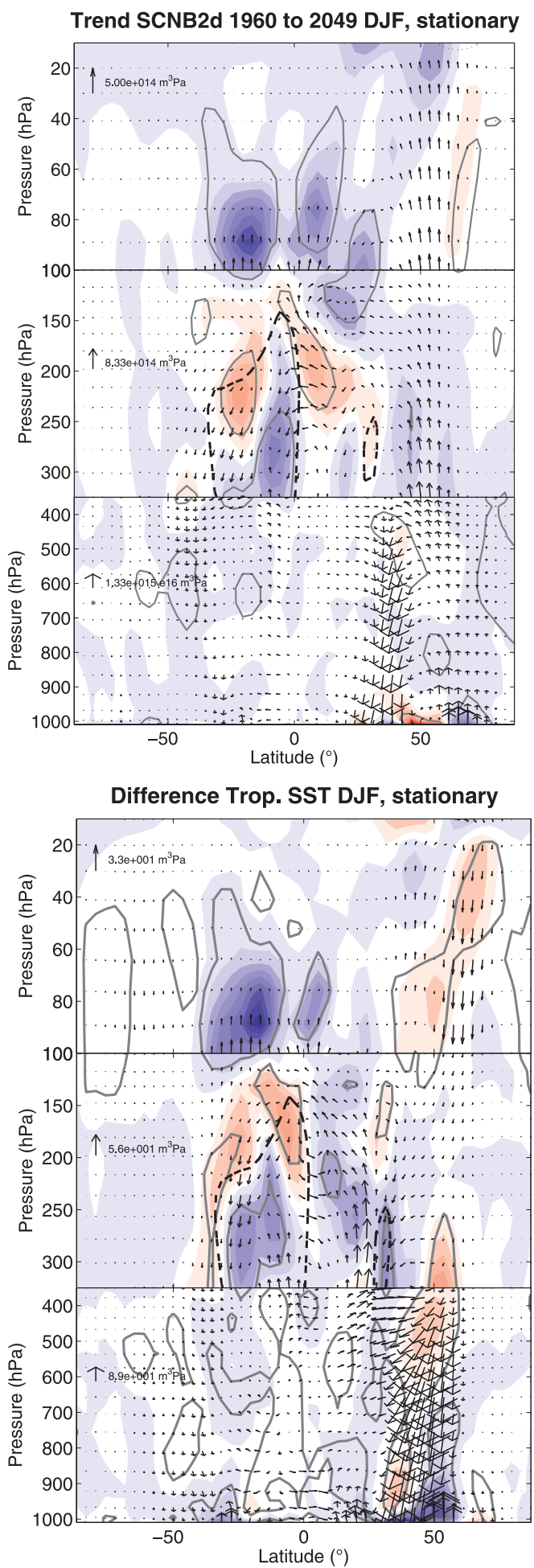

Trend SCNB2d 1960 to 2049 JJA,stationary
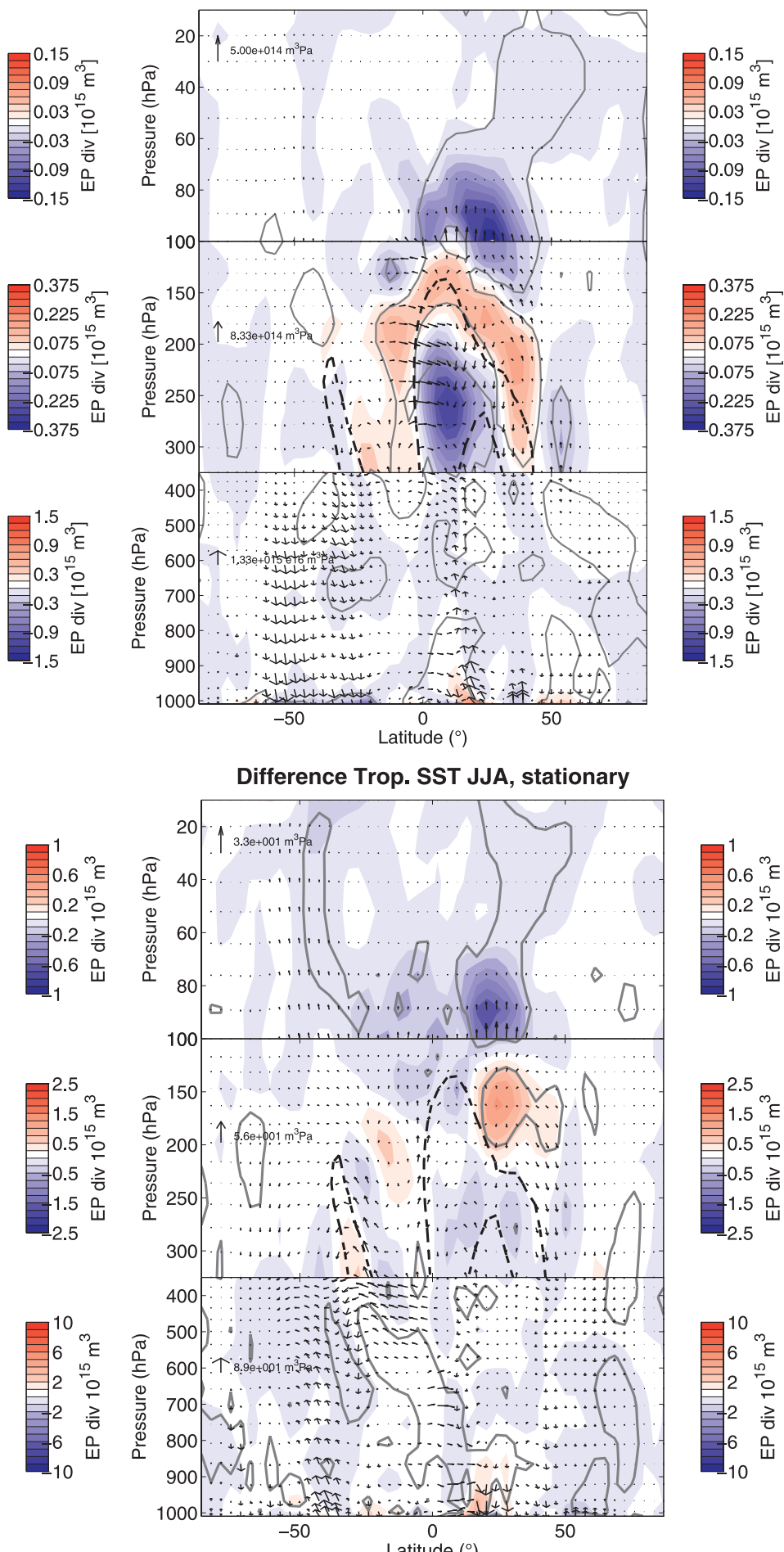

FIG. 10. (top) As in Fig. 8, but showing trends in EP fluxes of stationary waves over 1960-2049 in the transient simulation for (left) DJF and (right) JJA. (bottom) Response to changes in tropical SSTs (difference tropSST - Ref2000). Changes or trends are shown as change per decade and EP flux divergence changes are significant within the gray contours. The black dashed contour signifies regions of climatological EP flux divergence from 1960 to 1969 (contour line at $0.1 \times 10^{16} \mathrm{~m}^{3}$ ). 
lower levels $(\sim 275 \mathrm{hPa})$ and close to the equator, but a small region of increases in EP flux divergence is also apparent near $20^{\circ} \mathrm{S}$ at approximately $225 \mathrm{hPa}$. This trend pattern suggests a shift in the region of wave generation toward the subtropics during DJF. The region of positive trends in EP flux divergence around $10^{\circ} \mathrm{N}$ and $200 \mathrm{hPa}$ lies in a region of climatological EP flux convergence, indicating reduced EP flux convergence (waves are damped less strongly and can therefore propagate higher, apparent as upward EP flux trends).

During JJA, in the region of climatological wave generation in the upper troposphere, the trend is mostly significant and negative, indicating less generation of wave activity, especially at lower altitudes. Only near $150 \mathrm{hPa}$ does the EP flux divergence increase (i.e., the source region of EP flux divergence shifts slightly upward in JJA).

The extratropics, on the other hand, during both DJF and JJA show no significant changes in EP fluxes in the stratosphere. This implies that the increase in wave forcing by stationary waves is due to changes in the generation or propagation properties of tropical waves, while extratropical waves play a minor role.

As shown in Fig. 4, transient waves also contribute to the increase in the forcing of upwelling, especially during northern winter. For transient waves, the trend pattern in EP fluxes (not shown) suggests that changes in the upper tropical troposphere lead to the increased wave drag in the lower stratosphere subtropics while extratropical waves show no significant trends. The wave drag of transient waves in the lower stratosphere increases both in the summer and winter subtropics, with stronger increases in the respective summer hemisphere. So overall the increase in EP flux convergence is stronger in the subtropics of the summer hemisphere compared with the winter hemisphere. The strengthening of the residual circulation, however, is almost symmetric in the two hemispheres (Fig. 2). Downward control calculations of the changes in the pattern of the residual circulation (not shown) reveal that the changes above $80 \mathrm{hPa}$ in the summer subtropics, which are of opposite sign to the changes below, cannot be reproduced (i.e., are not due to resolved wave drag). This indicates that an additional forcing (most likely OGWD) drives changes in the summer subtropics of opposite sign to the changes induced by resolved wave drag, therewith somewhat counteracting the strengthening. This is consistent with the slight overestimation of the trend in tropical upwelling by DC (see Fig. 7). These superimposed changes can explain the symmetry in the circulation changes in the two hemispheres despite the stronger change in EP flux convergence during summer compared with winter.
The trend pattern in EP fluxes from the transient simulation is compared to the response in EP fluxes to changes in tropical SSTs in Fig. 10. The increase in upward EP fluxes and convergence in the summer subtropical lower stratosphere during both seasons, as a response to higher tropical SSTs, closely resembles the trends in the transient simulation. The increased EP flux into the stratosphere appears to originate from the tropics. In the extratropics a considerable response to tropical SST changes occurs only in the northern midlatitudes in DJF, where upward EP fluxes are reduced in the troposphere and stratosphere. This might be due to the artificially enhanced meridional temperature gradient (as only tropical SSTs are perturbed). Since this is not relevant for the problem studied here, it is not considered further.

During DJF, the difference pattern in the tropical upper troposphere broadly resembles the trend in the transient simulation. However, the EP flux divergence in the wave source region is weakened in a larger region, and an increase in EP flux divergence occurs only around 200-150 hPa and close to the equator. During JJA no significant changes are found in the wave source region. Here, the only change in the troposphere is a decrease in the EP flux convergence around $150 \mathrm{hPa}$ and $25^{\circ} \mathrm{N}$. The response in the lower stratosphere does, however, occur irrespective of the absence of changes in wave generation and closely resembles the trend in the transient simulation.

\section{2) EQUINOX SEASONS}

The climatology of EP fluxes for northern spring (MAM) is shown in Fig. 8. The general pattern for SON is mirrored about the equator but is otherwise qualitatively similar to MAM (not shown). The wave forcing in the lower stratosphere is, however, weaker during SON. The pattern during the equinox seasons is mostly hemispherically symmetric, with almost equally strong wave fluxes in the extratropics in both hemispheres being refracted toward the equator in the upper troposphere. Around the equinoxes the region of strong EP flux divergence (i.e., wave generation) in the tropical upper troposphere is much weaker than during the solstice seasons, but weak wave generation persists in the autumn hemisphere. This weak generation of stationary waves leads to weak EP flux convergence in the lower stratosphere inner tropics, while transient waves contribute to EP flux divergence at subtropical latitudes. The weaker generation of tropical waves explains the relatively weaker forcing by stationary waves during the equinox seasons compared with the solstice seasons (see Fig. 4).

As for DJF, EP fluxes in E39C-A agree qualitatively well with ERA-Interim in MAM. In both cases the transient waves show strong fluxes in the midlatitudes of both hemispheres. The tropical wave activity of 

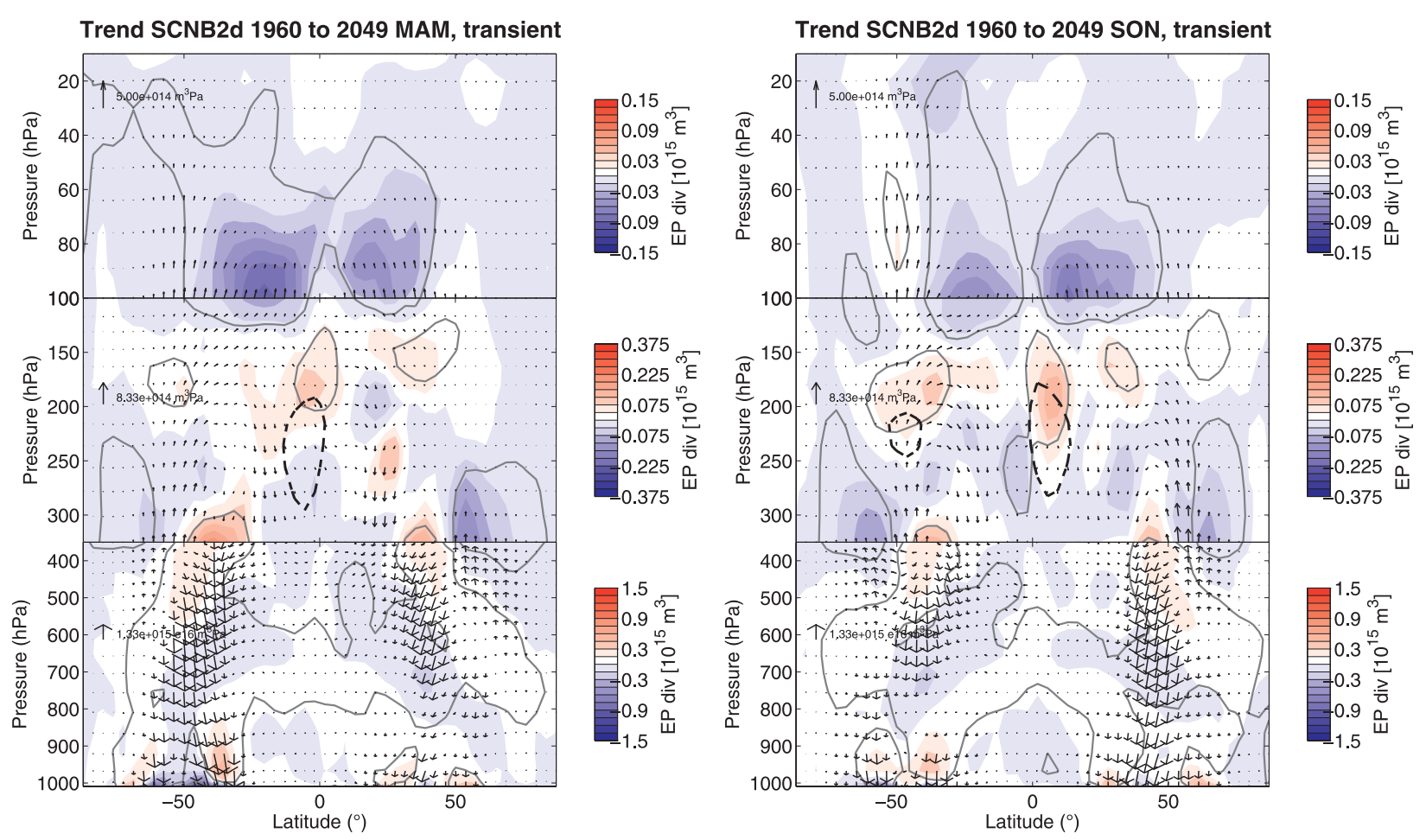

FIG. 11. As in Fig. 10 (top), but showing trends in EP fluxes of transient waves for (left) MAM and (right) SON.

stationary waves is reduced compared to DJF, more so in ERA-Interim than in E39C-A. This explains the more pronounced seasonality in the wave forcing of upwelling by stationary waves in ERA-Interim compared to E39C-A (as shown in Fig. 4).

The trends in the wave forcing of tropical upwelling around the equinoxes were found to be mostly due to transient waves (especially in northern spring). In particular, synoptic-scale waves have a local maximum in the forcing during the equinox seasons, and the forcing is enhanced in a future climate. Figure 11 shows the trends in EP fluxes of transient waves during the equinox seasons. Clearly, an increase in upward fluxes and therefore EP flux convergence in the lower stratosphere subtropics can be seen in both hemispheres during both MAM and SON. Some regions of decreased EP flux convergence (i.e., decreased dissipation) are apparent between 200 and $150 \mathrm{hPa}$. The wave fluxes in the extratropical lower troposphere decrease, such that the increase in tropical wave fluxes cannot be attributed to increased wave generation in the extratropical lower troposphere.

\section{Discussion}

\section{a. Changes in wave generation}

Enhanced wave driving during the solstice seasons is caused by increased wave convergence in the lower stratosphere of the summer hemisphere. The increased upward EP flux clearly originates from tropical waves. In the transient experiment, the changes in EP flux divergence in the upper troposphere are indicative of changes in the generation of tropical waves. While the generation is inhibited over large regions, a slight shift of the region of wave generation is found.

The anomalies in tropical SSTs lead to changes in the pattern of occurrence of deep convection (not shown). While the total number of convective events decreases with increasing SSTs, individual events strengthen (i.e., the single events have a stronger mean cloud updraft). These changes in the nature of convection, along with an increase in the evaporation of water at the surface due to higher SSTs, are likely to modify the strength and location of latent heat release. As wave generation is sensitive to the location of latent heat release (Norton 2006), a shift in the region of strong deep convection is likely to modify the tropical wave response.

The close agreement in wave response in the tropical lower stratosphere between the tropSST and transient experiments suggests that the processes associated with tropospheric warming by tropical SSTs drive the increase in the wave fluxes in the lower stratosphere. However, the patterns of changes in wave generation differed in the tropSST simulation. During DJF, tropical wave generation appeared to be largely suppressed by higher 

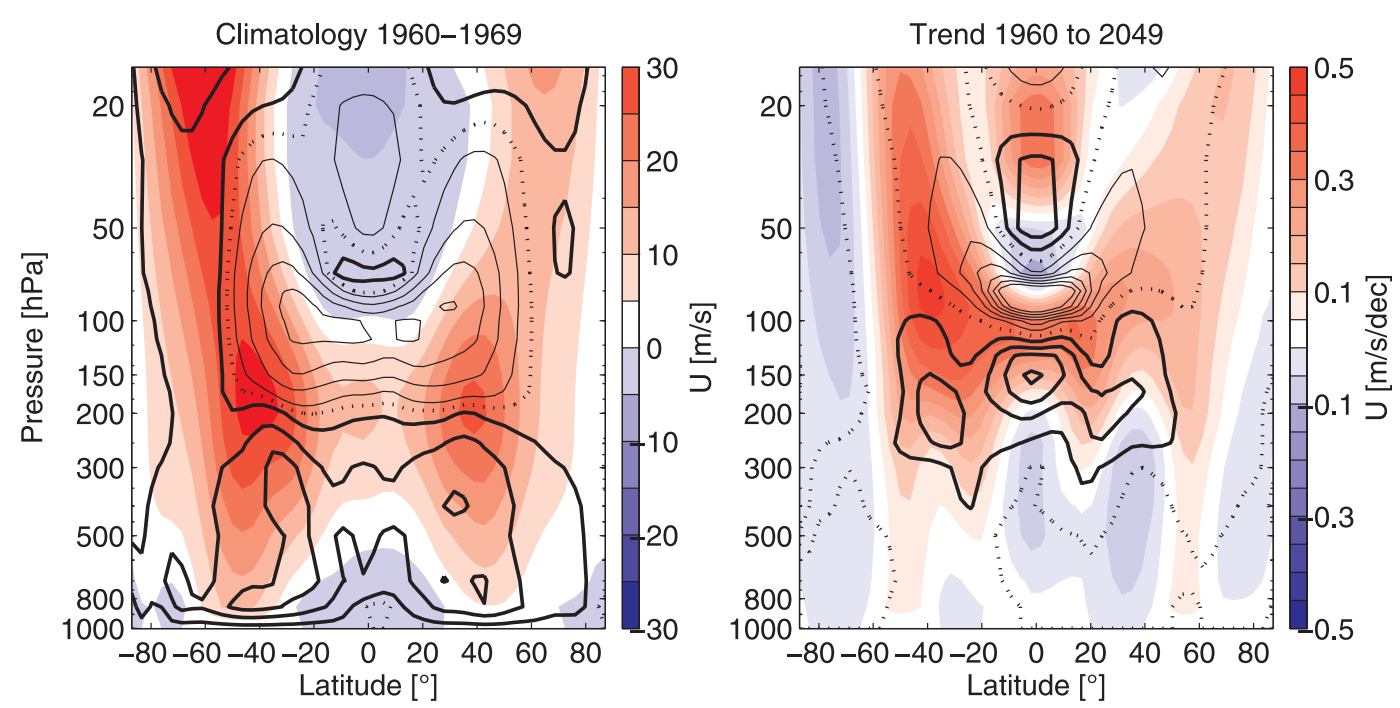

FIG. 12. (left) Climatological (1960-2049) annual mean of the zonal-mean zonal wind (color) with the vertical shear $d U / d z$ superimposed as contours. Thick (thin) lines denote positive (negative) values; the dotted line is the zero contour; contour interval is $0.5 \times 10^{-3} \mathrm{~s}^{-1}$. (right) Long-term trend (1960-2049) in the zonal wind and the vertical shear. Contour intervals for the vertical shear are $2.5 \times 10^{-5} \mathrm{~s}^{-1}$ decade $^{-1}$.

tropical SSTs but at the same time was shifted slightly toward higher levels. During JJA, on the other hand, no changes in tropical wave generation were found. The different behavior in the tropical upper troposphere in the transient and sensitivity experiments presumably arises from the different underlying time period and therefore different patterns of change in the SSTs. Analyzing trends from the transient simulation for subperiods of the whole simulation also reveals different behavior of the changes in wave generation in the tropical upper troposphere. Furthermore, with convection being parameterized in global models, projections of changes in convective activity and thus convective wave generation are uncertain and probably not robust. However, the signal in the lowermost stratosphere appears to be very robust and occurs irrespective of the nature of the changes in the wave source region in the upper troposphere. This suggests that changes in wave generation are not the determining factor in controlling changes in the wave flux into the lower stratosphere.

\section{b. Changes in wave propagation}

In addition to enhanced wave generation, changes in the ability of waves to propagate into the lower stratosphere can increase the EP flux convergence there.

In the climatological mean, the zonal mean wind increases with height below the level of the subtropical jets and decreases above, with a transition to easterly winds in the tropical lower stratosphere near $100 \mathrm{hPa}$ (Fig. 12). The strong EP flux convergence in the lower stratosphere and suppression of vertical wave propagation to altitudes above approximately $80 \mathrm{hPa}$ in the tropics indicates damping of quasi-stationary and westwardpropagating waves by the easterly background winds. In a changing climate, the strength of the subtropical jets increases and they are shifted upward and equatorward (Fig. 1). Winds become more westerly in the lower stratosphere and the zero wind line, as well as the region of easterly shear, shifts to higher levels (Fig. 12, right). These changes in the background winds lead to an upward shift of the region of dissipation of stationary and westward-propagating waves by both critical layer absorption and thermal damping. This leads to less wave dissipation in the upper troposphere, enhanced wave propagation to higher levels, and enhanced damping in the lower stratosphere.

While only the annual mean trend is shown in Fig. 12, changes are consistent throughout the year. The changes in the subtropical jets in response to tropical SST enhancement resembles the trend in the transient simulation (Fig. 1), and the difference pattern in the vertical shear of the zonal wind shows the same upward shift of the easterly shear zone as in the transient simulation (not shown). As the QBO phases in the two time-slice experiments compared here (tropSST and Ref2000) are identical, the difference pattern is due to the enhancement in tropical SSTs.

In the transient experiment, the jets are not only shifted upward but the locations of the strongest winds are also shifted equatorward, in particular in the lower stratosphere. This somewhat contradicts the results from recent studies on the widening of the tropics, including a poleward shift of the jets (Seidel et al. 2008). However, 


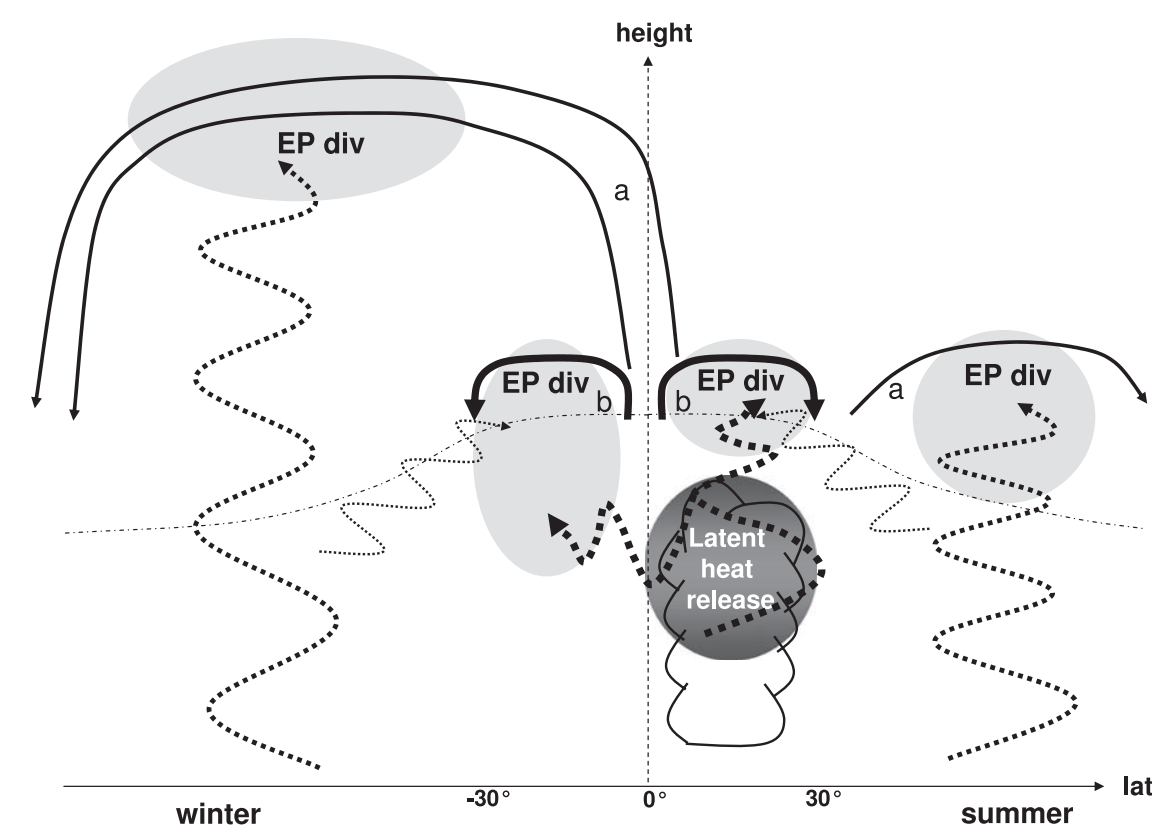

FIG. 13. Idealized schematic of the two branches of the meridional circulation in the stratosphere and its wave driving. Wave flux convergence is indicated as light gray patches (negative EP flux divergence). The global classical BDC (arrow a) is driven by extratropical waves and a deep hemisphere-wide cell exists in the winter hemisphere. The secondary circulation (arrow b) is confined to the (sub)tropical lower stratosphere and driven locally by wave dissipation. Both tropical waves, which are mostly generated by strong deep convection in the summer tropics, and extratropical waves, which are refracted to low latitudes, contribute to the wave flux convergence in the upper troposphere/lower stratosphere.

the change in wave propagation discussed here depends on the upward rather than the meridional shift of the jets. This can be seen in the tropSST simulation, where there is a robust wave response in the Southern Hemisphere despite a poleward-shifted jet (Fig. 1, right).

\section{Conclusions}

The forcing of tropical upwelling in the lower stratosphere by resolved waves was investigated in this study. It was shown that the amount of upwelling and its annual cycle is accounted for by resolved wave forcing that occurs locally in the (sub)tropics, in agreement with other recent studies (Boehm and Lee 2003; Kerr-Munslow and Norton 2006; Randel et al. 2008). While during the solstice seasons the major wave source is stationary planetary waves in the tropics, transient synoptic-scale waves that originate from the extratropics also contribute to tropical wave forcing, especially during northern spring. Tropical upwelling and its wave forcing in the model were compared to corresponding analysis with ERAInterim, and the overall findings based on the model could be confirmed. Therefore it can be assumed that the model adequately simulates processes in the tropical lower stratosphere, and thus estimated long-term trends can be regarded as reliable. These findings imply that in addition to the hemisphere-wide BDC, a more confined meridional circulation is superimposed in the tropics. While the BDC is driven by the well-known "extratropical wave pump" (Holton et al. 1995; Haynes et al. 1991), the tropical circulation is driven by local resolved wave forcing in the (sub)tropics. Ueyama and Wallace (2010) argue that extratropical waves are more important than tropical waves in driving the meridional circulation, which seems to contradict the results here. However, in Ueyama and Wallace (2010) the analyses focus on the drivers of the hemisphere-wide BDC rather than the shallow tropical circulation, emphasizing that it is important not to confuse these terms. This view of the meridional stratospheric circulations is illustrated in Fig. 13: the hemisphere-wide BDC that is driven by extratropical wave dissipation is superimposed by a shallow secondary circulation, which is driven by wave forcing in the (sub)tropical lower stratosphere (see also Birner and Bönisch 2011).

The analysis of the transient simulations performed with the model E39C-A showed that long-term increases in the residual circulation occur mainly in the tropical lower stratosphere (i.e., the "secondary" branch of the meridional circulation is strengthened). This 
finding agrees with other recent studies with different model systems, but in many models the increase in the meridional circulation extends to higher latitudes and altitudes (e.g., Butchart et al. 2010). Furthermore, not all models consistently show that resolved wave forcing is responsible for the increased forcing. However, this is in part due to the fact that different regions are analyzed in different studies. As mentioned in the introduction, resolved wave forcing was found to be the primary contributor to enhanced forcing in the lower stratosphere (McLandress and Shepherd 2009), in agreement with the results presented here. Gravity waves become more important in the middle stratosphere (McLandress and Shepherd 2009). Because gravity waves are parameterized in the models, they constitute a source of uncertainty (see, e.g., Sigmond and Scinocca 2010). E39C-A uses a parameterization for orographic gravity wave drag but neglects nonorographic gravity waves. In addition, the model is confined to the lower and middle stratosphere as it extends only up to $10 \mathrm{hPa}$. Therefore, it might well be that these limitations lead to the absence of simulated changes in the BDC in the middle stratosphere. As the strengthening of upwelling in the lower stratosphere appears to be a robust result across models while the changes in the hemisphere-wide BDC are not as consistent, it seems possible that this uncertainty results from different treatment of gravity waves in the models.

It was shown that the increase in the residual circulation is driven by changes in the troposphere due to the indirect effect of changes in SSTs. Therefore, it can be concluded that processes associated with tropospheric warming are responsible for the increase in tropical upwelling, confirming earlier studies by Fomichev et al. (2007), Sigmond et al. (2004), and Oman et al. (2009). Furthermore, the new and additional sensitivity simulations show that the region that triggers changes in upwelling is confined to the tropics. Changes in extratropical SSTs, on the other hand, result in almost no response in the stratosphere (not shown here). The increase in tropical SSTs leads both to enhanced subtropical jets due to the warming of the tropical troposphere and to changes in the distribution of convective latent heat release. Thus, both wave propagation and wave generation are modified and it is not possible to design a simulation with a free running model in which only the wave propagation or only the wave generation is perturbed.

It was found that the increase in local wave forcing in the tropics is due to both stationary and transient waves. The analyses indicate that the generation of planetary stationary waves during the solstice seasons is modified, but enhanced wave fluxes into the lower stratosphere also occurred in absence of wave generation changes. Modifications of wave generation might also contribute to the changes in wave forcing in the lower stratosphere, as suggested in Deckert and Dameris (2008). However, it became apparent that increased wave propagation into the lower stratosphere due to changes in the background winds is responsible for the changes in wave forcing. As changes in wave damping due to the background conditions act on stationary or westward-propagating waves despite their scale and frequency, this would explain the fact that the annual cycle in wave forcing by stationary and transient waves is not altered and tropical upwelling is found to increase throughout the year. If the only cause were changes in the generation of large-scale waves, it would be expected that tropical upwelling increases would occur mainly during the solstice seasons.

However, care has to be taken in assigning cause and effect of the dynamical changes in the tropics, since the zonal wind and wave drag are two-way coupled. Therefore it is very hard, if not impossible, to disentangle the cause-effect relationship of zonal wind changes and wave propagation and dissipation. Probably only studies with simpler mechanistic models, in which the strength of the jets can be adjusted and fixed, might be able to reveal the exact causal chain. Furthermore, the region of maximum changes in tropical upwelling coincides with the tropopause region. When considering trends in upwelling relative to the tropopause, they might be different, as the rising of the tropopause coincides with the strongest change in upwelling. The dynamical relation between the tropopause change and the increase in upwelling remains an open issue for future studies.

Since it is found that tropical SSTs drive changes in tropical upwelling by modifying tropical wave activity, it can be expected that similar mechanisms act as a response to El Niño-Southern Oscillation (ENSO). This was, however, not confirmed by Calvo et al. (2010), but further studies will be necessary to elucidate this question.

Acknowledgments. This study was funded by the Deutsche Forschungsgemeinschaft (DFG) through the DFG research group SHARP (Stratospheric Change and its Role for Climate Prediction). We thank U. Hamann and the two anonymous reviewers for helpful comments.

\section{REFERENCES}

Birner, T., and H. Bönisch, 2011: Residual circulation trajectories and transit times into the extratropical lowermost stratosphere. Atmos. Chem. Phys., 11, 817-827.

Boehm, M. T., and S. Lee, 2003: The implications of tropical Rossby waves for tropical tropopause cirrus formation and for the equatorial upwelling of the Brewer-Dobson circulation. J. Atmos. Sci., 60, 247-261. 
Butchart, N., and Coauthors, 2006: Simulations of anthropogenic change in the strength of the Brewer-Dobson circulation. Climate Dyn., 27, 727-741.

— and Coauthors, 2010: Chemistry-climate model simulations of 21st century stratospheric climate and circulations changes. J. Climate, 23, 5349-5374.

Calvo, N., and R. R. Garcia, 2009: Wave forcing of the tropical upwelling in the lower stratosphere under increasing concentrations of greenhouse gases. J. Atmos. Sci., 66, 3184-3196.

——, W. J. Randel, and D. R. Marsh, 2010: Dynamical mechanism for the increase in tropical upwelling in the lowermost tropical stratosphere during warm ENSO events. J. Atmos. Sci., 67, 2331-2340, doi:10.1175/2010JAS3433.1.

Dameris, M., and Coauthors, 2005: Long-term changes and variability in a transient simulation with a chemistry-climate model employing realistic forcing. Atmos. Chem. Phys., 5, 2121-2145.

Deckert, R., and M. Dameris, 2008: Higher tropical SSTs strengthen the tropical upwelling via deep convection. Geophys. Res. Lett., 35, L10813, doi:10.1029/2008GL033719.

Engel, A., and Coauthors, 2009: Age of stratospheric air unchanged within uncertainties over the past 30 years. Nature Geosci., 2, 28-31, doi:10.1038/ngeo388.

Eyring, V., and Coauthors, 2008: Overview of the new CCMVal reference and sensitivity simulations in support of upcoming ozone and climate assessments and planned SPARC CCMVal. SPARC Newsletter, No. 30, SPARC Office, Toronto, ON, Canada, 20-26. [Available online at http:// www.atmosp.physics.utoronto.ca/SPARC/newsletters.html.]

, T. G. Shepherd, and D. W. Waugh, Eds., 2010: SPARC report on the evaluation of chemistry-climate models. SPARC Tech. Rep. 5., WCRP-132, WMO/TD-1526. [Available online at http:// www.atmosp.physics.utoronto.ca/SPARC/ccmval_final/index. php.]

Fomichev, V. I., A. I. Jonsson, J. de Grandpré, S. R. Beagley, C. McLandress, K. Semeniuk, and T. G. Shepherd, 2007: Response of the middle atmosphere to $\mathrm{CO}_{2}$ doubling: Results from the Canadian Middle Atmosphere Model. J. Climate, 20, 1121-1144.

Fu, Q., S. Solomon, and P. Lin, 2010: On the seasonal dependence of tropical lower-stratospheric temperature trends. Atmos. Chem. Phys., 10, 2643-2653.

Garcia, R. R., and M. L. Salby, 1987: Transient response to localized episodic heating in the tropics. Part II: Far-field behavior. J. Atmos. Sci., 44, 499-532.

- , and W. Randel, 2008: Acceleration of the Brewer-Dobson circulation due to increases in greenhouse gases. J. Atmos. Sci., 65, 2731-2739.

Garny, H., M. Dameris, and A. Stenke, 2009: Impact of prescribed SSTs on climatologies and long-term trends in CCM simulations. Atmos. Chem. Phys., 9, 6017-6031.

Gettelman, M., and Coauthors, 2010: Multimodel assessment of the upper troposphere and lower stratosphere: Tropics and global trends. J. Geophys. Res., 115, D00M08, doi:10.1029/ 2009JD013638.

Gill, A. E., 1980: Some simple solutions for heat-induced tropical circulation. Quart. J. Roy. Meteor. Soc., 106, 447-462, doi:10.1256/ smsqj. 44904.

Haynes, P., C. Marks, M. McIntyre, T. Shepherd, and K. Shine, 1991: On the "downward control" of extratropical diabatic circulations by eddy-induced mean zonal forces. J. Atmos. Sci., 48, 651-678.

Hegglin, M. I., and Coauthors, 2010: Multi-model assessment of the upper troposphere and lower stratosphere: Extratropics. J. Geophys. Res., 115, D00M09, doi:10.1029/2010JD013884.
Hein, R., and Coauthors, 2001: Results of an interactively coupled atmospheric chemistry-general circulation model: Comparison with observations. Ann. Geophys., 19, 435-457.

Holton, J., P. Haynes, M. McIntyre, A. Douglass, R. Rood, and L. Pfister, 1995: Stratosphere-troposphere exchange. Rev. Geophys., 33, 403-439.

Houghton, J. T., Y. Ding, D. J. Griggs, M. Noguer, P. J. van der Linden, X. Dai, K. Maskell, and C. A. Johnson, Eds., 2001: Climate Change 2001: The Scientific Basis. Cambridge University Press, $881 \mathrm{pp}$.

Johns, T. C., and Coauthors, 2006: The new Hadley Centre climate model (HadGEM1): Evaluation of coupled simulations. J. Climate, 19, 1327-1353.

Kerr-Munslow, A. M., and W. A. Norton, 2006: Tropical wave driving of the annual cycle in tropical tropopause temperatures. Part I: ECMWF analyses. J. Atmos. Sci., 63, 14101419.

Land, C., J. Feichter, and R. Sausen, 2002: Impact of vertical resolution on the transport of passive tracers in the ECHAM4 model. Tellus, 54B, 344-360, doi:10.1034/j.1600-0889.2002. 201367.x.

Lee, S., 1999: Why are the climatological zonal winds easterly in the equatorial upper troposphere? J. Atmos. Sci., 56, 1353-1363.

Lin, P., Q. Fu, S. Solomon, and J. M. Wallace, 2009: Temperature trend patterns in Southern Hemisphere high latitudes: Novel indicators of stratospheric change. J. Climate, 22, 6325-6341.

Martin, G. M., M. A. Ringer, V. D. Pope, A. Jones, C. Dearden, and T. J. Hinton, 2006: The physical properties of the atmosphere in the new Hadley Centre Global Environmental Model (HadGEM1). Part I: Model description and global climatology. J. Climate, 19, 1274-1301.

McLandress, C., and T. G. Shepherd, 2009: Simulated anthropogenic changes in the Brewer-Dobson circulation, including its extension to high latitudes. J. Climate, 22, 1516-1540.

Miller, M. J., T. N. Palmer, and R. Swinbank, 1989: Parameterization and influence of sub-grid scale orography in general circulation and numerical weather prediction models. Meteor. Atmos. Phys., 40, 84-109.

Norton, W. A., 2006: Tropical wave driving of the annual cycle in tropical tropopause temperatures. Part II: Model results. J. Atmos. Sci., 63, 1420-1431.

Oman, L., D. W. Waugh, S. Pawson, R. S. Stolarski, and P. A. Newman, 2009: On the influence of anthropogenic forcings on changes in the stratospheric mean age. J. Geophys. Res., 114, D03105, doi:10.1029/2008JD010378.

Plumb, R. A., and J. Eluszkiewicz, 1999: The Brewer-Dobson circulation: Dynamics of the tropical upwelling. J. Atmos. Sci., 56, 868-890.

Randel, W. J., R. Garcia, and F. Wu, 2008: Dynamical balances and tropical stratospheric upwelling. J. Atmos. Sci., 65, 3584-3595.

Reithmeier, C., and R. Sausen, 2002: ATTILA: Atmospheric tracer transport in a Lagrangian model. Tellus, 54B, 278-299.

Seidel, D. J., Q. Fu, W. J. Randel, and T. J. Reichler, 2008: Widening of the tropical belt in a changing climate. Nat. Geosci., 1, 21-24, doi:10.1038/ngeo.2007.38.

Sigmond, M., and J. F. Scinocca, 2010: The influence of the basic state on the Northern Hemisphere circulation response to climate change. J. Climate, 23, 1434-1446.

_, P. C. Siegmund, E. Manzini, and H. Kelder, 2004: A simulation of the separate climate effects of middle-atmospheric and tropospheric $\mathrm{CO}_{2}$ doubling. J. Climate, 17, 2352-2367.

Simmons, A., S. Uppala, D. Dee, and S. Kobayashi, 2006: ERAInterim: New ECMWF reanalysis products from 1989 onwards. 
ECMWF Newsletter, No. 110, ECMWF, Reading, United Kingdom, 25-35.

Steil, B., M. Dameris, C. Brühl, P. J. Crutzen, V. Grewe, M. Ponater, and R. Sausen, 1998: Development of a chemistry module for GCMs: First results of a multiannual integration. Ann. Geophys., 16, 205-228.

Stenke, A., V. Grewe, and M. Ponater, 2008: Lagrangian transport of water vapour and cloud water in the ECHAM4 GCM and its impact on the cold bias. Climate Dyn., 31, 491-506, doi:10.1007/s00382-007-0347-5.
— M. Dameris, V. Grewe, and H. Garny, 2009: Implications of Lagrangian transport for coupled chemistry-climate simulations. Atmos. Chem. Phys., 9, 5489-5504.

Thompson, D. W. J., and S. Solomon, 2005: Recent stratospheric climate trends as evidenced in radiosonde data: Global structure and tropospheric linkages. J. Climate, 18, 47854795.

Ueyama, R., and J. M. Wallace, 2010: To what extent does highlatitude wave forcing drive tropical upwelling in the BrewerDobson circulation? J. Atmos. Sci., 67, 1232-1246. 